\title{
Rapamycin attenuated zinc-induced tau phosphorylation and oxidative stress in animal model: Involvement of dual mTOR/p70S6K and Nrf2/HO-1 pathways
}

\author{
Chencen Lai ${ }^{1,2 \dagger}$, Yuanting Ding ${ }^{2 \dagger}$, Qian Chen ${ }^{2 \dagger}$, Songbai $\mathrm{Su}^{2}$, Heng Liu ${ }^{3}$, Ruiqing $\mathrm{Ni}^{4,5}$, Zhi Tang $^{{ }^{*}}$
}

${ }^{1}$ Key Laboratory of Endemic and Ethnic Diseases, Ministry of Education \& Key Laboratory of Medical Molecula r Biology of Guizhou Province, Guizhou Medical University, Guiyang, China

${ }^{2}$ The First Affiliated Hospital of Guizhou University of Traditional Chinese Medicine, Guiyang, China

${ }^{3}$ Department of Anesthesiology, Tongren Municipal People's Hospital, Tongren 554300, Guizhou, China

${ }^{4}$ Institute for Regenerative Medicine, University of Zurich, Zurich, Switzerland

${ }^{5}$ Institute for Biomedical Engineering, ETH \& University of Zurich, Zurich, Switzerland

* Correspondence

Zhi Tang, MD, PhD

E-mail: tangzhi_2000@hotmail.com

$\dagger$ These authors have contributed equally to this work.

Keywords: Animal model, cognitive deficit, hyperphosphorylation, mTOR/p70S6K, Nrf2/HO-1, oxidative stress, rapamycin, Tau, Zinc 


\begin{abstract}
Alzheimer's disease is pathologically featured by abnormal accumulation of amyloid-beta plaque, neurofibrillary tangles, oxidative stress, neuroinflammation, and neurodegeneration. Metal dysregulation including excessive zinc released by presynaptic neurons plays an important role in tau pathology and oxidase activation. The activities of mammalian target of rapamycin (mTOR)/ ribosomal S6 protein kinase (p70S6K) are elevated in the brains of patients with Alzheimer's disease. Zinc induces tau hyperphosphorylation via mTOR/P70S6K activation in vitro. However, the involvement of mTOR/P70S6K pathway in zinc-induced oxidative stress, tau degeneration, synaptic and cognitive impairment, has not been fully elucidated in vivo. Here we assessed in the effect of pathological concentration of zinc in SH-SY5Y cells by using biochemical assays and immunofluorescence staining. Rats $(n=18$, male) were lateral ventricularly-injected with zinc and treated with rapamycin (intraperitoneal injection) for one week and assessed using Morris water maze. Evaluation of the oxidative stress, tau phorsphylation and synaptic impairment were performed using the hippocampus tissue of the rats by biochemical assays and immunofluorescence staining. Results from Morris water maze showed that the capacity of spatial memory is impaired in zinc-treated rats. Zinc sulfate significantly increased the levels of P-mTOR Ser2448, P-p70S6K Thr389, and P-tau Ser356, and decreased levels of Nrf2 and HO $\square 1$ in SHSY5Y cells and in zinc-treated rats compared with control groups. Increased expressions of reactive oxygen species were observed in zinc sulfate-induced SH-SY5Y cells as well as in the hippocampus of zinc-injected rats. Rapamycin, an inhibitor of mTOR, rescued the zinc-induced increases in mTOR/p70S6K activations, tau phosphorylation and oxidative stress, as well as $\mathrm{Nrf} 2 / \mathrm{HO} \square 1$ inactivation, cognitive impairment and synaptic impairment reduced the expression of synapse-related proteins in zinc-injected rats. In conclusion, our findings imply that rapamycin prevents zinc-induced cognitive impairment and protects neurons from tau pathology, oxidative stress and synaptic impairment, by decreasing mTOR/p70S6K hyperactivity and increasing Nrf2/HO $\square 1$ activity.
\end{abstract}




\section{Introduction}

Alzheimer's disease (AD) is pathologically featured by abnormal accumulation of amyloid-beta (A $\beta$ ) plaque, neurofibrillary tangles (NFTs), neuroinflammation, oxidative stress, synaptic impairment and neurodegeneration $(1,2)$. The pathological changes lead to cognitive decline and impairment in patients and in animal models $(3,4)$. The microtubule-associated protein tau is abnormally hyperphosphorylated and mainly aggregated into paired helical filaments (PHF) in brain from patients with $\mathrm{AD}(5,6)$. Tau hyperphosphorylation is mediated by protein kinases or phosphatases, which involves in AD neurofibrillary degeneration $(7,8)$. The mammalian targets of rapamycin (mTOR) and ribosomal S6 protein kinase (p70S6K) are serine/threonine kinases, which play key roles in the regulation of protein synthesis and degradation, to age-dependent cognitive decline and pathogenesis of AD (9-11). Accumulating evidence demonstrated abnormal mTOR signaling in the brain affects several pathways in $\mathrm{AD}$ which associated with metabolism, insulin signaling, protein aggregation, mitochondrial function and oxidative stress (12). Increased expressions of mTOR and P70S6K being colocalized with NFT and mediated tau phosphorylation (9-11, 13, 14). Rapamycin, a well-known inhibitor of mTOR, plays an important role for autophagy and insulin signaling $(15,16)$ and regulating of tau phosphorylation $(13,17,18)$. However, the upstream or downstream effectors that controlled by mTOR which contributed to the changes in neuronal functions and cognitive decline have not been fully elucidated.

Metal dysregulation, particularly iron, copper and zinc, is implicated in the development of AD at early stage (19-25). Higher level of cerebral zinc is observed in the post-mortem brain tissue from patients with AD (reaching 200-300 $\mu \mathrm{M}$ ) compared to that in healthy controls $(26,27)$. Zinc is the second abundant essential trace metals in the brain, critical for the maintaining the brain homeostasis $(19,27,28)$. Under pathological conditions, the excessive zinc released from the synaptic vesicle activation promotes tau hyperphosphorylation $(19,26,29,30)$ in cells $(13,31)$ and liquid-liquid phase separation of tau protein (32). In addition, previous studies have demonstrated that zinc firmly bind to $A \beta$ and was detected inside $A \beta$ plaque (33-36). In $\mathrm{AD}$ brain, presynaptic neurons release excessive zinc, which causes oxidase activation in neurons, and exacerbates the pathological development, leading to neuronal death $(29,30,37,38)$.

Oxidative stress is an early event in $\mathrm{AD}$ and play an important role in $\mathrm{AD}$ pathogenesis (39). Elevated level of reactive oxygen species (ROS) was detected in post-mortem brain tissues from $\mathrm{AD}$ patients and animal models of $\mathrm{AD}$ (40-42). The activation of nuclear factor erythroid 2-related factor 2 (Nrf2)/heme oxygenase-1 (HO-1) pathway inhibits the progression of inflammation, reduces ROS production, and thus has been a potential therapeutic target for AD (43-46). There is a vicious cycle formed by excessive zinc, tau and oxidative stress: elevated levels of zinc raises the production of ROS in mitochondria. The oxidative stress increases zinc concentration and tau hyperphosphorylation. In addition, excessive zinc and hyperphosphorylated tau cause oxidative stress and neurotoxicity. Hyperphosphorylated tau damages microtubule function and develops oxidative stress $(47,48)$; An increased oxidative stress has been indicated to cause tau hyperphosphorylation $(49,50)$, and aggravate neuronal death (51). Oxidative stress has been previously been shown as the underlying mechanism for the activation of mTOR in AD (52). However the underlying mechanism of how excessive zinc links to tau degeneration remains unclear. 
In the current study, we hypothesized that pathological concentration of zinc could disturb the rapamycin-dependent mTOR/P70S6K and Nrf2/HO $\square 1$ pathways, leading to detrimental effects in oxidative stress, tau hyperphosphorylation, synaptic and cognitive impairment. To this end, we assessed the effect of rapamycin treatment on the zinc sulfate $(300 \mu \mathrm{M})$ treated SH-SY5Y cells and lateral ventrally-injected rats.

\section{2, Materials and Methods}

\subsection{Materials and antibodies}

Zinc sulfate, rapamycin, trisaminomethane (Tris), radioimmunoprecipitation assay (RIPA), sodium dodecyl sulphate (SDS) buffer and protease inhibitor cocktail were obtained from Sigma Aldrich Co. (St, Louis, MO, USA). A Bradford kit was purchased from Bio-rad (California, USA). The primary antibodies employed in the present study, please refer to Supplementary Table 1.

\subsection{Cell culture and treatment}

The cell culture is prepared as described previously $(13,53)$. Human SH-SY5Y neuroblastoma cells were grown to $70-80 \%$ confluence in $75 \mathrm{~cm}^{2}$ plastic culture flasks (Corning, China) in a mixture of $5 \% \mathrm{CO} 2$ and $95 \%$ air at $37{ }^{\circ} \mathrm{C}$, employing Dulbecco's modified Eagle's medium (DMEM)/F12 medium (1:1) supplemented with $10 \%$ fetal bovine serum (FBS), 100 units/mL penicillin, and $100 \mathrm{mg} / \mathrm{mL}$ streptomycin. Prior to treating the SH-SY5Y cells with $300 \mu \mathrm{M}$ zinc sulfate, the cultures were kept in free serum media. $300 \mu \mathrm{M}$ zinc sulfate is chosen based on the results and protocol established from our previous study (54). The SH-SY5Y neuroblastoma cells were pretreated with $20 \mathrm{ng} / \mathrm{mL}$ rapamycin for $1 \mathrm{~h}$, then incubated with $300 \mu \mathrm{M}$ zinc sulfate for $4 \mathrm{~h}$.

\subsection{Animals}

Eighteen Sprague-Dawley (SD) rats were included in this study (male, weight 250-300 g, 12 months-of-age, Guizhou experimental Animal Center in China). All rats were housed in ventilated cages under in a climate-controlled room (temperature: $22 \pm 2{ }^{\circ} \mathrm{C}$, humidity: $50 \pm 5 \%, 12 \mathrm{~h}$ lightdark cycle with lights on at 08:00). Food (Safe, sterilized) and water (softened, sterilized) were provided ad libitum. Poplar wood shavings were placed in cages as environmental enrichments. All experimental protocols were approved by the Guiyang regional Animal Care center and Ethics Committee.

\subsection{Surgery and treatment}

Timeline of the surgery, treatment and behavior testing are shown in Supplementary Figure 1. All rats were randomly assigned into three groups (control group, zinc group, and zinc+rapamycin group, $\mathrm{n}=6$ each group). Rats were deeply anesthetized with an initial dose of $5 \%$ isoflurane in oxygen/air mixture $(1: 4,1 \mathrm{~L} / \mathrm{min})$ and were maintained at $1.5 \%$ isoflurane in oxygen/air mixture $(1: 4,0.6 \mathrm{~L} / \mathrm{min})$. Anesthetized rats were placed on a stereotaxic apparatus (RWD Life Science, Shenzhen, China) and the coordinates for injection were $0.8 \mathrm{~mm}$ posterior and $1.5 \mathrm{~mm}$ lateral and $3.6 \mathrm{~mm}$ ventral from the bregma. Zinc sulfate $(25 \mathrm{mM}, 2 \mu \mathrm{l})$ was injected slowly into the right 
lateral ventricle in rats from both $\mathrm{Zn}$ and $\mathrm{Zn}+$ Rapamycin group (Figure 1A). Rats in control group underwent the same surgical procedures and were injected with phosphate-buffered saline (PBS, $\mathrm{pH}$ 7.4) of the same volume, respectively. Body temperature and respiratory rate of the rats were monitored during surgery. Body temperature of the animal was maintained at $36.5 \pm 0.5^{\circ} \mathrm{C}$ throughout the procedure using a warming pad. Lidocaine ointment was wiped locally to the scalp to reduce the pain. One day after the surgery, rats in the zinc+rapamycin group were administered with rapamycin $(1.5 \mathrm{mg} / \mathrm{kg}$ body weight, intraperitoneal injection (i.p,), three times for one week). The rats in the control and $\mathrm{Zn}$ group were injected with $0.9 \%$ citrate buffer of the same volume (i.p.). Behavioral tests were performed subsequently after rapamycin treatment period.

\subsection{Behavioral Testing}

Morris water maze (MWM) was used to assess the hippocampal spatial learning function of the rats (55). The circular pool (160 cm diameter and $50 \mathrm{~cm}$ height) was filled to a depth of $30 \mathrm{~cm}$ with water $\left(25 \pm 1^{\circ} \mathrm{C}\right)$ in this study. Visual cues were positioned above water level and extra maze cues were blocked with a dark curtain. During Morris water maze training, all rats were subjected to 4 training trials daily for six consecutive days. In each trial, rats were trained to find a hidden platform (20 cm diameter) which submerged $1 \mathrm{~cm}$ under the water surface for $60 \mathrm{~s}$. Afterwards the rats were kept to stay on the platform for $20 \mathrm{~s}$. If these rats could not seek the platform within $60 \mathrm{~s}$, they were guided to the platform within $60 \mathrm{~s}$ and kept to stay on the platform for $20 \mathrm{~s}$ afterwards. On day 7, a spatial probe trial was executed, where the platform was removed. The escape latency, the total of time spent in the target quadrant, the number of crossing platform, and swimming speed was monitored by video tracking software (ANY-maze, USA).

After the behavioral tests, all rats were then sacrificed under deep anesthesia with pentobarbital sodium (50 mg/kg body weight), and transcardiacly perfused with PBS (pH 7.4). Brains were removed from the skull afterwards. The left hemisphere brain tissue was saved for western blot and stored at $-80^{\circ} \mathrm{C}$. The right hemisphere rat brain tissue was fixed in $4 \%$ paraformaldehyde in $1 \times$ PBS (pH 7.4) for $24 \mathrm{~h}$ and saved in $1 \times \mathrm{PBS}(\mathrm{pH} 7.4)$ at $4{ }^{\circ} \mathrm{C}(56)$, For immunofluorescent staining, the fixed right brain hemisphere tissues were dehydrated using vacuum infiltration processor (Leica ASP200S, Germany), and embedded in paraffin using the Arcadia H heated embedding workstation (Leica, Germany).

\subsection{Protein extraction and western blotting}

The SH-SY5Y cells ( $n=3$ cell samples in each group) and the hippocampus of rats $(n=6$ in each group) were lysed in RIPA buffer with a $0.1 \%$ protease inhibitors cocktail on ice. Protein concentration was measured by a Bradford kit (Bio-rad). The proteins were analyzed by Western blotting as described earlier (13). The lysates were separated on 7.5-15\% SDS-PAGE gel, and the bands transferred onto $0.22 / 0.45 \mu \mathrm{m}$ polyvinylidene difluoride (PVDF) membranes. After blocking the membranes with $5 \%$ milk, the membranes were incubated with primary antibodies

(Supplementary Table 1) at $4{ }^{\circ} \mathrm{C}$ overnight. The PVDF membranes were washed, and then with secondary peroxidase coupled anti-mouse or anti-rabbit antibodies (1:5000) at room temperature for $1 \mathrm{~h}$ (13). Immunoreactive bands were visualized by Immobilon Western Horseradish peroxidase substrate luminol reagent (Millipore) using a ChemiDoc ${ }^{\mathrm{TM}}$ MP imaging system (Bio-rad, USA). 


\subsection{DCFH-DA staining}

ROS generation was measured via 2'-7'dichlorofluorescin diacetate (DCFH-DA) staining for detecting the intracellular hydrogen peroxide and oxidative stress (Beyotime, China). Following treatment and washing with PBS, the SH-SY5Y cells were incubated with DCFH-DA probes at $37^{\circ} \mathrm{C}$ for $30 \mathrm{~min}$. The intracellular accumulation of fluorescent DCF was imaged using by confocal microscopy (Leica, SP8, Germany).

\subsection{Immunofluorescent staining and confocal imaging}

After treatment, the SH-SY5Y cells were plated on coverslips were rinsed with PBS, and then were fixed in $4 \%$ paraformaldehyde for $30 \mathrm{~min}$. Cells were permeabilized in $0.1 \%$ Triton X-100 in Tris-buffered saline (TBS) for $10 \mathrm{~min}$. The unspecific binding sites were blocked with blocking solution (5\% bovine serum albumin, $0.1 \%$ Triton X-100 in TBS) for $1 \mathrm{~h}$. Cells were incubated with primary antibodies, anti-4-hydroxynonenal (4-HNE) and anti-8-hydroxy-2'-deoxyguanosine (8-OHdG), at $4 \square$ overnight. After washing with TBS, bound antibody was detected by incubation for $1 \mathrm{~h}$ with Alexa Fluor 546-IgGs or Alexa Fluor 488-IgGs (1:200 for both, Invitrogen, USA).

Coronal sections of the rat brains were cut at $6 \mu \mathrm{m}$ using a microtome (Leica RM2245, Germany). Dewaxed and rehydrated hippocampal sections were blocked in TBST (TBS with Tween20) with $5 \%$ bovine serum albumin for $1 \mathrm{~h}$, then incubated with the primary antibody against 8-OHdG at $4{ }^{\circ} \mathrm{C}$ overnight. After washing, the sections were incubated with AlexaFluor488 anti-mouse IgGs (1:200, Invitrogen, USA) for $1 \mathrm{~h}$. After washing with TBS, the sections and coverslips were mounted by vector anti-fading mounting medium (Vector Laboratories, Burlingame, CA, USA). The fluorescent intensity was imaged using Leica SP8 confocal microscopy at $40 \times$ magnification. The mean fluorescent intensity was quantified using Image J 1.49V software (NIH, US).

\subsection{Statistical analysis}

Statistical analysis was executed using SPSS software (version 23.0) or GraphPad Prism 8.0 software. The results were presented as mean \pm SEM. Morris water maze behavior data were assessed by two-way repeated measure ANOVA. The other parameters were executed using oneway ANOVA followed by LSD's post-hoc test for multiple comparisons. Significance was set at p $<0.05$.

\section{Results}

\subsection{Downregulation of mTOR/P70S6K and upregulation of $\mathrm{Nrf} 2 / \mathrm{HO} \square 1$ pathways are involved in the protection by rapamycin against the toxic effects of zinc sulfate both in SH- SY5Y cells and in rats}

First, we assess the potential involvement of mTOR/P70S6K pathway in the alterations by zinc sulfate treatment in SH- SY5Y cells and zinc sulfate-injected rats. Zinc sulfate significantly elevated the levels of phosphorylated mTOR (S2448) by around $20 \%$, and phosphorylated P70S6K (T389) by $300 \%$ in SH-SY5Y cells $\mathrm{p}=0.015$ and $\mathrm{p}=0.0001$ respectively, zinc sulfate- 
treated compared to control group (Figs. 1A, B). Pre-treatment with rapamycin $(20 \mathrm{ng} / \mathrm{mL})$ abolished the effect of zinc sulfate on the levels of mTOR (S2448), and phosphorylated P70S6K (T389) in SH $\square$ SY5Y cells, $\mathrm{p}=0.01$ and $\mathrm{p}=0.0001$ respectively, zinc-treated compared to zinc+rapamycin treated group (Figures 1A, B). The total levels of mTOR remained unaltered in the presence of zinc as well as zinc+rapamycin pretreatment in cell (Figures 1A, B). Additionally, we found that zinc sulfate treatment induced an increase of total P70S6K protein in the zinc sulfate-treated cells compared with control cells, $p=0.01$ (Figure 1A). Rapamycin pretreatment $(20 \mathrm{ng} / \mathrm{mL})$ did not affect the increased levels of total P70S6K protein induced by zinc sulfate in cells.

Zinc sulfate $(300 \mu \mathrm{M})$ significantly elevated the levels of phosphorylated mTOR (S2448), and phosphorylated P70S6K (T389) by $25 \%$ and $30 \%$ in the hippocampus of the zinc-injected rats compared to control, $\mathrm{p}=0.001, \mathrm{p}=0.005$ respectively (Figures 1E, F). Rapamycin treatment attenuated the effect of zinc sulfate on mTOR (S2448), and phosphorylated P70S6K (T389) in rats, $\mathrm{p}=0.0001, \mathrm{p}=0.026$ (zinc vs. zinc+rapamycin group) (Figures 1E, F). Both the levels of total mTOR and total P70S6K protein remained unaltered in the presence of zinc sulfate as well as zinc+ rapamycin pretreatment in all three groups of rats (Figures 1E, F).

Next, we assess the potential involvement of Nrf2 and $\mathrm{HO} \square 1$ pathway in the zinc induced alterations using SH- SY5Y cells and zinc-induced rats (Figures 1C-D, G-H). Zinc sulfate (300 $\mu \mathrm{M})$ significantly reduced the levels of Nrf2 by approximately $70 \%$, and $\mathrm{HO} \square 1$ by $30 \%$ in $\mathrm{SH} \square \mathrm{SY} 5 Y$ cells $\mathrm{p}=0.0003$, and $\mathrm{p}=0.016$ (Figures 1C, D). Pre-treatment with rapamycin (20 $\mathrm{ng} / \mathrm{mL}$ ) attenuated the effect of zinc sulfate on levels of $\mathrm{Nrf} 2$, and $\mathrm{HO} \square 1, \mathrm{p}=0.001$ and $\mathrm{p}=0.043$ in SH $\square$ SY5Y cells, zinc-treated compared to zinc+rapamycin treated group (Figures 1C, D).

In the hippocampus of zinc-injected rats, zinc sulfate $(300 \mu \mathrm{M})$ significantly reduced the levels of Nrf2 and $\mathrm{HO} \square 1$ by approximately $20 \%$ and $30 \%, \mathrm{p}=0.031$ and $\mathrm{p}=0.04$, zinc injected $v s$.

zinc+rapamycin group (Figures 1G, H). Rapamycin treatment abolished the effect of zinc sulfate on levels of $\mathrm{Nrf} 2$, and $\mathrm{HO} \square 1, \mathrm{p}=0.04$ and $\mathrm{p}=0.04$ in rats, zinc injected $v s$. zinc+rapamycin group (Figures 1G, H). Hence the neuroprotective effects of rapamycin were linked to the inactivation of the mTOR/P70S6K and activation of the $\mathrm{Nrf} 2 / \mathrm{HO} \square 1$ signaling pathways as defensive responses to oxidative stress.

\subsection{Rapamycin ameliorates tau hyperphosphorylation in zinc-induced SH-SY5Y cells and rats}

Next we assess the potential rapamycin protection against zinc induced tau hyperphosphorylation using SH- SY5Y cells and zinc-injected rats. We found that zinc treatment led to increased level of hyperphosphorylated tau at Ser356 (by $100 \%$ ) in zinc-treated SH-SY5Y cells compared to control, $\mathrm{p}=0.005$. Rapamycin treatment completely restored the level of phosphorylated tau S356 in SHSY5Y cells, $p=0.003$ zinc-treated compared to zinc+rapamycin treated group. The total tau levels showed no change in the presence of zinc or zinc+rapamycin compared to control group in cells (Figures 2A, B).

Moreover, zinc led to increased level of hyperphosphorylated tau at Ser356 in the hippocampus of zinc-injected rats by $80 \%, p=0.001$ (Figure 2C, D). Rapamycin treatment decreased the level of 
phosphorylated tau S356 by $40 \%$ in zinc-injected rats compared to zinc+rapamycin group, $\mathrm{p}=$ 0.031. The total tau levels showed no change in the presence of zinc or zinc+rapamycin in rats (Figures 2C, D).

\subsection{Rapamycin attenuates oxidative stress damage in SH-SY5Y cells and in the hippocampus of zinc induced rats}

Next we assessed the oxidative stress by immunofluorescence staining using DCFH-DA, $4 \square \mathrm{HNE}$ (lipid peroxidation), and $8 \square \mathrm{OHdG}$ (oxidation of DNA) in SH-SY5Y cells. Following exposure to zinc sulfate, the level of fluorescence intensity of DCFH-DA, 4 $\square \mathrm{HNE}$ and $8 \square \mathrm{OHdG}$ elevated in the zinc-treated group compared to the control group in SH-SY5Y cells, $p=0.0001, p=0.0001, p$ $=0.0001$ respectively (Figures 3A, B, 4A, B and 5A, B). Prior treatment with rapamycin neutralized the zinc-induced increase in fluorescence intensity of DCFH-DA, 4 $\square \mathrm{HNE}$ and $8 \square \mathrm{OHdG}$, zinc-treated group compared to zinc+rapamycin group in SH-SY5Y cells, $\mathrm{p}=0.0004, \mathrm{p}$ $=0.0003, \mathrm{p}=0.0004$ respectively (Figures 3A, B, 4A, B and 5A, B).

To determine oxidative stress damage induced by zinc in vivo in rats, we measured the levels of 4HNE by using western blot in the hippocampal brain tissue homogenates from rats. Zinc led to an increased level of 4-HNE in the hippocampus of zinc-injected rats, $p=0.005$, compared to control group (Figure 4C, D). Rapamycin treatment decreased the level of 4-HNE in zinc-injected rats compared to zinc+rapamycin group, $\mathrm{p}=0.04$ (Figures 4C, D). We further measured the levels of $8-\mathrm{OHdG}$ products by immunofluorescence staining using in the hippocampal brain tissue slices from rats. Zinc led to an increased level of $8-\mathrm{OHdG}$ in the hippocampus of zinc-injected rats, $\mathrm{p}=$ 0.001 compared to control group (Figure 5C, D). Rapamycin treatment decreased the level of 4$\mathrm{HNE}$, and $8-\mathrm{OHdG}$ by in zinc-injected rats compared to zinc+rapamycin group, $\%, \mathrm{p}=0.038$ (Figures 5C, D).

\subsection{Rapamycin rescued impaired learning and memory in zinc-induced rats}

The spatial learning and memory function of the rats were assessed by using MWM test. The escape latency significantly increased in the zinc-injected rats compared to control on Day 5 and Day 6 ( $\mathrm{p}=0.031, \mathrm{p}=0.024$ respectively) (Figure 6A). On Day 7 , the time spent in the target quadrant and the number of platform location crossings both decreased by approximately $50 \%$ in zinc-induced rats compared to the control group $(\mathrm{p}=0.027$ and $\mathrm{p}=0.039)$ (Figures 6B, D).

Treatment with rapamycin led to a reduced escape latency in zinc + rapamycin rats compared to the zinc-injected rats on Day 5 and Day $6(\mathrm{p}=0.021, \mathrm{p}=0.033$ respectively). On Day 7 , the time spent in the target quadrant and the numbers of platform location crossings are increased compared to zinc-injected rats $(\mathrm{p}=0.044, \mathrm{p}=0.044)$, (Figures 6B, D). To study if zinc could affect the motion ability of rats, the swimming speed of rats were recorded. No differences were observed among the three groups (Figure 6C), implying that treatment with rapamycin and zinc did not radically affect the motion ability of rats.

\subsection{Rapamycin protected the synapses in zinc-induced SH-SY5Y cells and in rats}

Next we assessed the potential effect of rapamycin on zinc-induced synaptic impairment using SHSY5Y cells and zinc-induced rats. The expression levels of presynaptic proteins (SNAP 25 and 
synaptophysin) and postsynaptic protein (PSD 95) are indicator of the synaptic function. We found that zinc treatment led to reduced levels of SNAP 25, synaptophysin and PSD 95 in SH-SY5Y cells zinc treated compared to control, $p=0.039, p=0.004$ and $p=0.04$ respectively. Rapamycin treatment reversed the reduction in the levels of synaptophysin and PSD 95 induced by zinc in SHSY5Y cells $\mathrm{p}=0.03, \mathrm{p}=0.0001$, and $\mathrm{p}=0.035$ (zinc-treated group compared to zinc+rapamycin group)(Figures 7A, B). The levels of SNAP 25 recovered back to the control level, although were not significantly different from the zinc-treated cells.

Moreover, zinc injection led to reduced levels of SNAP 25, synaptophysin and PSD 95 in the hippocampus of zinc-injected rats, $p=0.001, p=0.04, p=0.013$ respectively (Figures 7C, D). Rapamycin treatment decreased the level of SNAP 25, synaptophysin and PSD 95 in zinc-injected rats compared to zinc+rapamycin group, $\mathrm{p}=0.038, \mathrm{p}=0.006, \mathrm{p}=0.009$ respectively (Figures 7C, D).

\section{Discussion}

Our data reveal that zinc leads to tau hyperphosphorylation, oxidative stress and synaptic impairment involving mTOR/P70S6K activation and $\mathrm{Nrf} 2 / \mathrm{HO} \square 1$ inactivation. Rapamycin ameliorates the zinc-induced tau hyperphosphorylation, oxidative stress damage and synaptic impairment, as well as rescues spatial learning deficits via down-regulating mTOR/P70S6K activities and up-regulating $\mathrm{Nrf} 2 / \mathrm{HO} \square 1$ activities.

Zinc has been closely related to the cognitive function, play an important role under physiological condition. Elevated levels of zinc ion were found in AD brains, notably in the hippocampus, cortex, and amygdale, which are severely affected by NFTs (19, 57-59). Accumulation evidence have shown a tight relationship of zinc with tau degeneration and cognitive impairment in human patients (60). Dietary zinc supplementation treatment in 3xTg-AD mice has been shown increased BDNF levels and prevented cognitive deficits as well as mitochondrial dysfunction (61).

Pathological level of zinc promotes tau tangle pathology in the brain of hAPP/htau (62), and tau mouse models (63). Targeting metals abnormal accumulation has been shown to rescue the pathology and phenotype in transgenic mouse models of tauopathy (64).

In the present study, we found that excessive zinc could induce dependent-mTOR(S2448)P70S6K(T389) phosphorylation and tau hyperphosphorylation both in cultured neuroblastoma SHSY5Y cells. Rapamycin suppress mTOR(S2448)/P70S6K(T389) phosphorylation and ameliorate tau pathology. We found that lateral ventricular injection of zinc sulfate could induce a persistent mTOR(S2448)-P70S6K(T389) phosphorylation in the rats' hippocampus, and that rapamycin reversed both mTOR(S2448) and P70S6K(T389) phosphorylation, and reduced the level of tau hyperphosphorylation. These results implied that zinc played a crucial role in tau pathology via regulating mTOR/P70S6K pathway and rapamycin exerted a beneficial effect on tau pathology.

mTOR or P70S6K is one of the most important serine/threonine kinase in eukaryotic cells, which plays a prominent role in the regulation of protein synthesis, phosphorylation, and autophagy (11, 65-69). We have previously showed increased expressions of p-mTOR(S2448) and pP70S6K(T389) in post-mortem AD brains, which associated with accumulation of hyperphosphorylated tau in $\operatorname{AD}(13,14,70)$. This suggests that phosphorylation of mTOR at S2448 
and P70S6K at T389 is a vital target for disease intervention. Zinc has been indicated in the mechanisms of mTOR/P70S6K activation in AD. We have previously shown that zinc treatment $(300 \mu \mathrm{M})$ promoted tau phosphorylation in vitro in cell cultures (13). Other study demonstrated that synaptic zinc promoted tau hyperphosphorylation (30), and accelerated the fibrillization of mutant $\Delta \mathrm{K} 280$ of full-length human tau, inducing apoptosis and toxicity in SH-SY5Y cells via bridging Cys-291 and Cys-322 (71). In addition, zinc binds to protein phosphatase 2A and induces its inactivation and tau hyperphosphorylation through Src dependent PP2A (tyrosine 307) phosphorylation (72). In ApoE4 transgenic mice, the tau hyperphosphorylation is associated with activation of extracellular signal-regulated kinase that modulated by zinc (73).

Oxidative stress has been recognized as a causative factor in various neurodegenerative diseases $(41,42,44,45)$. Excessive zinc triggers oxidase activation, and further generates oxidative products in neurons $(19,27)$. Pathological tau damages mitochondrial function resulting in increased ROS products and causing oxidative stress $(26,27,74,75)$. Increased productions of ROS causes lipid peroxidation and DNA damage, and in turn, could affect the hyperphosphorylation of tau, leading to a vicious cycle $(42,49,75-77)$. Here we investigate the mechanism of the zinc-mediated tau pathology in AD and whether excessive zinc could exacerbate the vicious cycle through mTOR/P70S6K pathway. The levels of oxidative products were assessed by immunostaining or western blot in the present study. We found an increasing level of ROS accumulation in zinc-treated SH-SY5Y cells, a marked increased expressions of lipid peroxidation product (4-HNE) and nucleic peroxidation product $(8-\mathrm{OHdG})$ in both zinc-induced SH-SY5Y cells and zinc-injected rats. Employing rapamycin pre-administration, the level of ROS, 4-HNE and 8OHdG was decreased in zinc-treated SH-SY5Y cells and zinc-injected rats.

Nrf2 is a transcription factor that negatively regulates the level of ROS to protect against oxidative stress damage. Ramsey et al. reported a significant decline in the level of Nrf2 in the brain from patients with $\mathrm{AD}$ (78). Several natural compounds havee been shown reduced oxidative stress in AD models through the Nrf2/HO-1 pathway $(79,80)$. We found rapamycin reverted the reduced level of Nrf2 /HO-1 in zinc-induced SH-SY5Y cells and rats, in line with previous observation (81). Rapamycin also rescued oxidative stress caused by tau hyperphosphorylation associated with inactive mTOR/P70S6K signaling pathway and active Nrf2/HO-1 signaling pathway.

The altered mTOR or P70S6K has been directly correlated to learning and memory in animal models $(15,82-84)$. Caccamo and Oddo et al. found that inhibition of mTOR by rapamycin could improve learning and memory, and reduce $\mathrm{A} \beta$ and tau pathology in $3 \times \mathrm{Tg}$-AD mice $(85,86)$. Chronic treatment with rapamycin enhances learning and memory in young adult mice, and improves age-related cognitive decline in older mice, possibly by activating major monoamine pathways in brain (87). In the present study, we show that an increased mTOR/P70S6K signaling in hippocampus of rat. Rapamycin treatment rescued the abnormal mTOR/P70S6K signaling to and improved the spatial learning in rats. Moreover we showed that rapamycin treatment reversed the decreased expression levels of synaptic proteins SNAP 25, synaptophysin and PSD 95 both in cell culture and in rats. Accumulating evidence have shown that rapamycin improved the cognitive decline in mouse model of Down syndrome $(\mathbf{1 5}, \mathbf{8 8}, \mathbf{8 9})$, amyloidosis (J20) (90-93), tauopathy $(\mathbf{1 7}, \mathbf{9 4}, \mathbf{9 5})$. Despite its compelling preclinical record, no clinical trials have tested rapamycin in patients with $\mathbf{A D}(\mathbf{9 6 , 9 7 )}$. 
There are several limitations in the study. Firstly, only MWM test was used to assess the spatial learning function of the rats. Further study using a panel of behaviour tests will provide comprehensive insights into the effect of rapamycin on zinc induced cognitive impairment. Secondly, we focused on the involvement of mTOR/p70S6K and Nrf2/HO-1 pathway in the current study, while many other pathways have been implicated in the effect elicited by zinc and rapamycin. Moreover, an acute effect of zinc and rapamycin treatment was investigated in the current study. The effect of chronic or environmental zinc exposure and treatment using rapamycin via oral intake remains to be investigated. The advance in non-invasive imaging has enabled detection of metal accumulation in vivo by using magnetic resonance imaging (98). Longitudinal study using in vivo imaging of the treatment effect on tau, neuroinflammation, ROS in animal model will provide further provide systematic insights $(25,54,99-104)$.

\section{Conclusions}

In conclusion, zinc treatment induces mTOR/p70S6K activation and Nrf2/HO-1 inactivation, tau hyperphosphorylation, oxidative stress damage in SH-SY5Y cells and spatial learning impairment in rats. Rapamycin attenuate mTOR/p70S6k and increase Nrf2/HO-1 activity, attenuates tau pathology, oxidative stress and cognitive deficits induced by zinc in a rat model. Rapamycin might be a viable treatment for zinc related neuronal and synaptic damage.

\section{Conflict of Interest}

The authors declare that there is no conflict of interests regarding the publication of this paper.

\section{Author Contributions}

ZT contributed to the conception and study design. CCL, YTD and QC performed the experiments. HL and SBS contributed to data collection and data analysis. RN, ZT interpreted the data. CCL, YTD, RN, and ZT wrote the manuscript. All authors approved the manuscript before submission.

\section{Funding}

This work was supported by the Chinese National Natural Science Foundation (81560241), China Postdoctoral Science Foundation (2020M683659XB), and the Foundation for Science and Technology projects in Guizhou ([2020]1Y354), Scientific Research Project of Guizhou University of Traditional Chinese Medicine ([2019]48).

\section{References}

1. P. Scheltens, B. De Strooper, M. Kivipelto, H. Holstege, G. Chételat, C. E. Teunissen, J. Cummings and W. M. van der Flier: Alzheimer's disease. The Lancet, 397(10284), 1577-1590 (2021) doi:10.1016/S0140-6736(20)32205-4

2. R. Zhou, B. Ji, Y. Kong, L. Qin, W. Ren, Y. Guan and R. Ni: PET Imaging of Neuroinflammation in Alzheimer's Disease. Frontiers in Immunology, 12, 3750 (2021)

3. P. Vagenknecht, M. Ono, A. Luzgin, B. Ji, M. Higuchi, D. Noain, C. Maschio, J. Sobek, Z. Chen, U. Konietzko, J. Gerez, R. Roland, R. M. Nitsch, D. Razansky, J. Klohs, X. L. Dean-Ben 
and R. Ni: Non-invasive imaging of tau-targeted probe uptake by whole brain multi-spectral optoacoustic tomography. bioRxiv, 2021.07.10.451626 (2021) doi:10.1101/2021.07.10.451626

4. A. Massalimova, R. Ni, R. M. Nitsch, M. Reisert, D. von Elverfeldt and J. Klohs: Diffusion Tensor Imaging Reveals Whole-Brain Microstructural Changes in the P301L Mouse Model of Tauopathy. Neurodegener Dis, 1-12 (2021) doi:10.1159/000515754

5. C. W. Chang, E. Shao and L. Mucke: Tau: Enabler of diverse brain disorders and target of rapidly evolving therapeutic strategies. Science, 371(6532) (2021) doi:10.1126/science.abb8255

6. G. S. Gibbons, V. M. Y. Lee and J. Q. Trojanowski: Mechanisms of Cell-to-Cell Transmission of Pathological Tau: A Review. JAMA Neurol, 76(1), 101-108 (2019) doi:10.1001/jamaneurol.2018.2505

7. K. Iqbal, F. Liu and C. X. Gong: Tau and neurodegenerative disease: the story so far. Nat Rev Neurol, 12(1), 15-27 (2016) doi:10.1038/nrneurol.2015.225

8. L. Martin, X. Latypova, C. M. Wilson, A. Magnaudeix, M. L. Perrin, C. Yardin and F. Terro: Tau protein kinases: involvement in Alzheimer's disease. Ageing Res Rev, 12(1), 289-309 (2013) doi:10.1016/j.arr.2012.06.003

9. S. Oddo: The role of mTOR signaling in Alzheimer disease. Front Biosci (Schol Ed), 4, 941-52 (2012)

10. J. J. Pei, C. Bjorkdahl, H. Zhang, X. Zhou and B. Winblad: p70 S6 kinase and tau in Alzheimer's disease. J Alzheimers Dis, 14(4), 385-92 (2008)

11. J. J. Pei and J. Hugon: mTOR-dependent signalling in Alzheimer's disease. J Cell Mol Med, 12(6B), 2525-32 (2008) doi:10.1111/j.1582-4934.2008.00509.x

12. M. Perluigi, F. Di Domenico, E. Barone and D. A. Butterfield: mTOR in Alzheimer disease and its earlier stages: Links to oxidative damage in the progression of this dementing disorder. Free Radic Biol Med, 169, 382-396 (2021) doi:10.1016/j.freeradbiomed.2021.04.025

13. Z. Tang, E. Bereczki, H. Zhang, S. Wang, C. Li, X. Ji, R. M. Branca, J. Lehtio, Z. Guan, P. Filipcik, S. Xu, B. Winblad and J. J. Pei: Mammalian target of rapamycin (mTor) mediates tau protein dyshomeostasis: implication for Alzheimer disease. J Biol Chem, 288(22), 15556-70 (2013) doi:10.1074/jbc.M112.435123

14. W. L. An, R. F. Cowburn, L. Li, H. Braak, I. Alafuzoff, K. Iqbal, I. G. Iqbal, B. Winblad and J. J. Pei: Up-regulation of phosphorylated/activated p70 S6 kinase and its relationship to neurofibrillary pathology in Alzheimer's disease. Am J Pathol, 163(2), 591-607 (2003) doi:10.1016/S0002-9440(10)63687-5

15. A. Tramutola, C. Lanzillotta, E. Barone, A. Arena, I. Zuliani, L. Mosca, C. Blarzino, D. A. Butterfield, M. Perluigi and F. Di Domenico: Intranasal rapamycin ameliorates Alzheimer-like cognitive decline in a mouse model of Down syndrome. Transl Neurodegener, 7, 28 (2018) doi:10.1186/s40035-018-0133-9

16. R. A. Saxton and D. M. Sabatini: mTOR Signaling in Growth, Metabolism, and Disease. Cell, 169(2), 361-371 (2017) doi:10.1016/j.cell.2017.03.035

17. C. Frederick, K. Ando, K. Leroy, C. Héraud, V. Suain, L. Buée and J. P. Brion: Rapamycin ester analog CCI-779/Temsirolimus alleviates tau pathology and improves motor deficit in mutant tau transgenic mice. J Alzheimers Dis, 44(4), 1145-56 (2015) doi:10.3233/jad-142097

18. H. Querfurth and H. K. Lee: Mammalian/mechanistic target of rapamycin (mTOR) complexes in neurodegeneration. Mol Neurodegener, 16(1), 44 (2021) doi:10.1186/s13024-021-00428-5

19. L. Wang, Y. L. Yin, X. Z. Liu, P. Shen, Y. G. Zheng, X. R. Lan, C. B. Lu and J. Z. Wang: Current understanding of metal ions in the pathogenesis of Alzheimer's disease. Transl 
Neurodegener, 9, 10 (2020) doi:10.1186/s40035-020-00189-Z

20. F. Moynier, M. L. Borgne, E. Laoud, B. Mahan, F. Mouton-Ligier, J. Hugon and C. Paquet: Copper and zinc isotopic excursions in the human brain affected by Alzheimer's disease. Alzheimers Dement (Amst), 12(1), e12112 (2020) doi:10.1002/dad2.12112

21. S. L. Sensi, A. Granzotto, M. Siotto and R. Squitti: Copper and Zinc Dysregulation in Alzheimer's Disease. Trends Pharmacol Sci, 39(12), 1049-1063 (2018) doi:10.1016/j.tips.2018.10.001

22. D. Enache, J. B. Pereira, V. Jelic, B. Winblad, P. Nilsson, D. Aarsland and E. Bereczki: Increased Cerebrospinal Fluid Concentration of ZnT3 Is Associated with Cognitive Impairment in Alzheimer's Disease. J Alzheimers Dis, 77(3), 1143-1155 (2020) doi:10.3233/jad-200498

23. K. D. Fasae, A. O. Abolaji, T. R. Faloye, A. Y. Odunsi, B. O. Oyetayo, J. I. Enya, J. A. Rotimi, R. O. Akinyemi, A. J. Whitworth and M. Aschner: Metallobiology and therapeutic chelation of biometals (copper, zinc and iron) in Alzheimer's disease: Limitations, and current and future perspectives. Journal of Trace Elements in Medicine and Biology, 67, 126779 (2021) doi:https://doi.org/10.1016/j.jtemb.2021.126779

24. N. Solovyev, A. H. El-Khatib, M. Costas-Rodríguez, K. Schwab, E. Griffin, A. Raab, B. Platt, F. Theuring, J. Vogl and F. Vanhaecke: $\mathrm{Cu}, \mathrm{Fe}$, and Zn isotope ratios in murine Alzheimer's disease models suggest specific signatures of amyloidogenesis and tauopathy. J Biol Chem, 296, 100292 (2021) doi:10.1016/j.jbc.2021.100292

25. R. Ni, Y. Zarb, G. A. Kuhn, R. Müller, Y. Yundung, R. M. Nitsch, L. Kulic, A. Keller and J. Klohs: SWI and phase imaging reveal intracranial calcifications in the P301L mouse model of human tauopathy. Magma, 33(6), 769-781 (2020) doi:10.1007/s10334-020-00855-3

26. C. J. Frederickson, J. Y. Koh and A. I. Bush: The neurobiology of zinc in health and disease. Nat Rev Neurosci, 6(6), 449-62 (2005) doi:10.1038/nrn1671

27. S. L. Sensi, P. Paoletti, A. I. Bush and I. Sekler: Zinc in the physiology and pathology of the CNS. Nat Rev Neurosci, 10(11), 780-91 (2009) doi:10.1038/nrn2734

28. D. Religa, D. Strozyk, R. A. Cherny, I. Volitakis, V. Haroutunian, B. Winblad, J. Naslund and A. I. Bush: Elevated cortical zinc in Alzheimer disease. Neurology, 67(1), 69-75 (2006) doi:10.1212/01.wnl.0000223644.08653.b5

29. L. Besser, E. Chorin, I. Sekler, W. F. Silverman, S. Atkin, J. T. Russell and M. Hershfinkel: Synaptically released zinc triggers metabotropic signaling via a zinc-sensing receptor in the hippocampus. J Neurosci, 29(9), 2890-901 (2009) doi:10.1523/JNEUROSCI.5093-08.2009

30. X. Y. Sun, Y. P. Wei, Y. Xiong, X. C. Wang, A. J. Xie, X. L. Wang, Y. Yang, Q. Wang, Y. M. Lu, R. Liu and J. Z. Wang: Synaptic released zinc promotes tau hyperphosphorylation by inhibition of protein phosphatase 2A (PP2A). J Biol Chem, 287(14), 11174-82 (2012) doi:10.1074/jbc.M111.309070

31. W. L. An, C. Bjorkdahl, R. Liu, R. F. Cowburn, B. Winblad and J. J. Pei: Mechanism of zincinduced phosphorylation of p70 S6 kinase and glycogen synthase kinase 3beta in SH-SY5Y neuroblastoma cells. J Neurochem, 92(5), 1104-15 (2005) doi:10.1111/j.1471-4159.2004.02948.x

32. V. Singh, L. Xu, S. Boyko, K. Surewicz and W. K. Surewicz: Zinc promotes liquid-liquid phase separation of tau protein. J Biol Chem, 295(18), 5850-5856 (2020) doi:10.1074/jbc.AC120.013166

33. R. A. Cherny, C. S. Atwood, M. E. Xilinas, D. N. Gray, W. D. Jones, C. A. McLean, K. J. Barnham, I. Volitakis, F. W. Fraser, Y. Kim, X. Huang, L. E. Goldstein, R. D. Moir, J. T. Lim, K. Beyreuther, H. Zheng, R. E. Tanzi, C. L. Masters and A. I. Bush: Treatment with a copper-zinc 
chelator markedly and rapidly inhibits beta-amyloid accumulation in Alzheimer's disease transgenic mice. Neuron, 30(3), 665-76 (2001) doi:10.1016/s0896-6273(01)00317-8

34. W. P. Esler, E. R. Stimson, J. M. Jennings, J. R. Ghilardi, P. W. Mantyh and J. E. Maggio: Zinc-induced aggregation of human and rat beta-amyloid peptides in vitro. J Neurochem, 66(2), 723-32 (1996) doi:10.1046/j.1471-4159.1996.66020723.x

35. A. L. Friedlich, J. Y. Lee, T. van Groen, R. A. Cherny, I. Volitakis, T. B. Cole, R. D. Palmiter, J. Y. Koh and A. I. Bush: Neuronal zinc exchange with the blood vessel wall promotes cerebral amyloid angiopathy in an animal model of Alzheimer's disease. J Neurosci, 24(13), 3453-9 (2004) doi:10.1523/jneurosci.0297-04.2004

36. S. Zirah, S. A. Kozin, A. K. Mazur, A. Blond, M. Cheminant, I. Ségalas-Milazzo, P. Debey and S. Rebuffat: Structural changes of region 1-16 of the Alzheimer disease amyloid beta-peptide upon zinc binding and in vitro aging. $J$ Biol Chem, 281(4), 2151-61 (2006) doi:10.1074/jbc.M504454200

37. S. S. Rao, L. Lago, R. Gonzalez de Vega, L. Bray, D. J. Hare, D. Clases, P. A. Doble and P. A. Adlard: Characterising the spatial and temporal brain metal profile in a mouse model of tauopathy. Metallomics, 12(2), 301-313 (2020) doi:10.1039/c9mt00267g

38. T. Furuta, C. Ohshima, M. Matsumura, N. Takebayashi, E. Hirota, T. Mawaribuchi, K. Nishida and K. Nagasawa: Oxidative stress upregulates zinc uptake activity via Zrt/Irt-like protein 1 (ZIP1) in cultured mouse astrocytes. Life Sci, 151, 305-312 (2016) doi:10.1016/j.lfs.2016.03.025

39. M. Mittal, M. R. Siddiqui, K. Tran, S. P. Reddy and A. B. Malik: Reactive oxygen species in inflammation and tissue injury. Antioxidants \& redox signaling, 20(7), 1126-1167 (2014) doi:10.1089/ars.2012.5149

40. W. Wang, F. Zhao, X. Ma, G. Perry and X. Zhu: Mitochondria dysfunction in the pathogenesis of Alzheimer's disease: recent advances. Molecular Neurodegeneration, 15(1), 30 (2020) doi:10.1186/s13024-020-00376-6

41. M. T. Islam: Oxidative stress and mitochondrial dysfunction-linked neurodegenerative disorders. Neurol Res, 39(1), 73-82 (2017) doi:10.1080/01616412.2016.1251711

42. E. Niedzielska, I. Smaga, M. Gawlik, A. Moniczewski, P. Stankowicz, J. Pera and M. Filip: Oxidative Stress in Neurodegenerative Diseases. Mol Neurobiol, 53(6), 4094-4125 (2016) doi:10.1007/s12035-015-9337-5

43. A. Loboda, M. Damulewicz, E. Pyza, A. Jozkowicz and J. Dulak: Role of Nrf2/HO-1 system in development, oxidative stress response and diseases: an evolutionarily conserved mechanism. Cellular and molecular life sciences : CMLS, 73(17), 3221-3247 (2016) doi:10.1007/s00018-0162223-0

44. A. Singh, R. Kukreti, L. Saso and S. Kukreti: Oxidative Stress: A Key Modulator in Neurodegenerative Diseases. Molecules, 24(8) (2019) doi:10.3390/molecules24081583

45. E. Tönnies and E. Trushina: Oxidative Stress, Synaptic Dysfunction, and Alzheimer's Disease. J Alzheimers Dis, 57(4), 1105-1121 (2017) doi:10.3233/jad-161088

46. P. R. Angelova, N. Esteras and A. Y. Abramov: Mitochondria and lipid peroxidation in the mechanism of neurodegeneration: Finding ways for prevention. Med Res Rev, 41(2), 770-784 (2021) doi:10.1002/med.21712

47. D. C. David, S. Hauptmann, I. Scherping, K. Schuessel, U. Keil, P. Rizzu, R. Ravid, S. Drose, U. Brandt, W. E. Muller, A. Eckert and J. Gotz: Proteomic and functional analyses reveal a mitochondrial dysfunction in P301L tau transgenic mice. J Biol Chem, 280(25), 23802-14 (2005) doi:10.1074/jbc.M500356200 
48. V. Garcia-Escudero, P. Martin-Maestro, G. Perry and J. Avila: Deconstructing mitochondrial dysfunction in Alzheimer disease. Oxid Med Cell Longev, 2013, 162152 (2013) doi:10.1155/2013/162152

49. S. Melov, P. A. Adlard, K. Morten, F. Johnson, T. R. Golden, D. Hinerfeld, B. Schilling, C. Mavros, C. L. Masters, I. Volitakis, Q. X. Li, K. Laughton, A. Hubbard, R. A. Cherny, B. Gibson and A. I. Bush: Mitochondrial oxidative stress causes hyperphosphorylation of tau. PLoS One, 2(6), e536 (2007) doi:10.1371/journal.pone.0000536

50. E. Trushina and C. T. McMurray: Oxidative stress and mitochondrial dysfunction in neurodegenerative $\quad$ diseases. $\quad$ Neuroscience, $145(4), \quad 1233-48 \quad$ (2007) doi:10.1016/j.neuroscience.2006.10.056

51. Y. Cheng and F. Bai: The Association of Tau With Mitochondrial Dysfunction in Alzheimer's Disease. Front Neurosci, 12, 163 (2018) doi:10.3389/fnins.2018.00163

52. S. Majd and J. H. T. Power: Oxidative Stress and Decreased Mitochondrial Superoxide Dismutase 2 and Peroxiredoxins 1 and 4 Based Mechanism of Concurrent Activation of AMPK and mTOR in Alzheimer's Disease. Curr Alzheimer Res, 15(8), 764-776 (2018) doi:10.2174/1567205015666180223093020

53.

54. C. Qian, L. Chencen, C. Fa, D. Yuanting, Z. Yiyuan, S. Songbai, N. Ruiqing and T. Zhi. BMC Neuroscience (2021) doi:10.21203/rs.3.rs-829075/v1

55. C. V. Vorhees and M. T. Williams: Morris water maze: procedures for assessing spatial and related forms of learning and memory. Nature protocols, 1(2), 848-858 (2006) doi:10.1038/nprot.2006.116

56. Y. Ding, H. Liu, M. Cen, Y. Tao, C. Lai and Z. Tang: Rapamycin Ameliorates Cognitive Impairments and Alzheimer's Disease-Like Pathology with Restoring Mitochondrial Abnormality in the Hippocampus of Streptozotocin-Induced Diabetic Mice. Neurochem Res, 46(2), 265-275 (2021) doi:10.1007/s11064-020-03160-6

57. M. A. Deibel, W. D. Ehmann and W. R. Markesbery: Copper, iron, and zinc imbalances in severely degenerated brain regions in Alzheimer's disease: possible relation to oxidative stress. $J$ Neurol Sci, 143(1-2), 137-42 (1996)

58. B. Strodel and O. Coskuner-Weber: Transition Metal Ion Interactions with Disordered Amyloid- $\beta$ Peptides in the Pathogenesis of Alzheimer's Disease: Insights from Computational Chemistry Studies. J Chem Inf Model, 59(5), 1782-1805 (2019) doi:10.1021/acs.jcim.8b00983

59. P. Wang and Z. Y. Wang: Metal ions influx is a double edged sword for the pathogenesis of Alzheimer's disease. Ageing Res Rev, 35, 265-290 (2017) doi:10.1016/j.arr.2016.10.003

60. D. R. Whitfield, J. Vallortigara, A. Alghamdi, D. Howlett, T. Hortobágyi, M. Johnson, J. Attems, S. Newhouse, C. Ballard, A. J. Thomas, J. T. O'Brien, D. Aarsland and P. T. Francis: Assessment of ZnT3 and PSD95 protein levels in Lewy body dementias and Alzheimer's disease: association with cognitive impairment. Neurobiol Aging, 35(12), 2836-2844 (2014) doi:10.1016/j.neurobiolaging.2014.06.015

61. C. Corona, F. Masciopinto, E. Silvestri, A. D. Viscovo, R. Lattanzio, R. L. Sorda, D. Ciavardelli, F. Goglia, M. Piantelli, L. M. Canzoniero and S. L. Sensi: Dietary zinc supplementation of 3xTg-AD mice increases BDNF levels and prevents cognitive deficits as well as mitochondrial dysfunction. Cell Death Dis, 1(10), e91 (2010) doi:10.1038/cddis.2010.73

62. S. L. P. Lippi, M. L. Smith and J. M. Flinn: A Novel hAPP/htau Mouse Model of Alzheimer's Disease: Inclusion of APP With Tau Exacerbates Behavioral Deficits and Zinc Administration 
Heightens Tangle Pathology. Front Aging Neurosci, 10, 382 (2018) doi:10.3389/fnagi.2018.00382 63. K. M. Craven, W. R. Kochen, C. M. Hernandez and J. M. Flinn: Zinc Exacerbates Tau Pathology in a Tau Mouse Model. J Alzheimers Dis, 64(2), 617-630 (2018) doi:10.3233/jad180151

64. A. Sedjahtera, L. Gunawan, L. Bray, L. W. Hung, J. Parsons, N. Okamura, V. L. Villemagne, K. Yanai, X. M. Liu, J. Chan, A. I. Bush, D. I. Finkelstein, K. J. Barnham, R. A. Cherny and P. A. Adlard: Targeting metals rescues the phenotype in an animal model of tauopathy. Metallomics, 10(9), 1339-1347 (2018) doi:10.1039/c8mt00153g

65. R. J. Griffin, A. Moloney, M. Kelliher, J. A. Johnston, R. Ravid, P. Dockery, R. O'Connor and C. O'Neill: Activation of Akt/PKB, increased phosphorylation of Akt substrates and loss and altered distribution of Akt and PTEN are features of Alzheimer's disease pathology. J Neurochem, 93(1), 105-17 (2005) doi:10.1111/j.1471-4159.2004.02949.x

66. G. Y. Liu and D. M. Sabatini: mTOR at the nexus of nutrition, growth, ageing and disease. Nat Rev Mol Cell Biol, 21(4), 183-203 (2020) doi:10.1038/s41580-019-0199-y

67. I. Bjedov and C. Rallis: The Target of Rapamycin Signalling Pathway in Ageing and Lifespan Regulation. Genes (Basel), 11(9) (2020) doi:10.3390/genes11091043

68. S. Yin, L. Liu and W. Gan: The Roles of Post-Translational Modifications on mTOR Signaling. Int J Mol Sci, 22(4) (2021) doi:10.3390/ijms22041784

69. J. Bockaert and P. Marin: mTOR in Brain Physiology and Pathologies. Physiol Rev, 95(4), 1157-87 (2015) doi:10.1152/physrev.00038.2014

70. X. Li, I. Alafuzoff, H. Soininen, B. Winblad and J. J. Pei: Levels of mTOR and its downstream targets 4E-BP1, eEF2, and eEF2 kinase in relationships with tau in Alzheimer's disease brain. FEBS J, 272(16), 4211-20 (2005) doi:10.1111/j.1742-4658.2005.04833.x

71. J. Y. Hu, D. L. Zhang, X. L. Liu, X. S. Li, X. Q. Cheng, J. Chen, H. N. Du and Y. Liang: Pathological concentration of zinc dramatically accelerates abnormal aggregation of full-length human Tau and thereby significantly increases Tau toxicity in neuronal cells. Biochim Biophys Acta Mol Basis Dis, 1863(2), 414-427 (2017) doi:10.1016/j.bbadis.2016.11.022

72. Y. Xiong, X. P. Jing, X. W. Zhou, X. L. Wang, Y. Yang, X. Y. Sun, M. Qiu, F. Y. Cao, Y. M. Lu, R. Liu and J. Z. Wang: Zinc induces protein phosphatase $2 \mathrm{~A}$ inactivation and tau hyperphosphorylation through Src dependent PP2A (tyrosine 307) phosphorylation. Neurobiol Aging, 34(3), 745-56 (2013) doi:10.1016/j.neurobiolaging.2012.07.003

73. F. M. Harris, W. J. Brecht, Q. Xu, R. W. Mahley and Y. Huang: Increased tau phosphorylation in apolipoprotein E4 transgenic mice is associated with activation of extracellular signal-regulated kinase: modulation by zinc. J Biol Chem, 279(43), 44795-801 (2004) doi:10.1074/jbc.M408127200

74. C. J. Frederickson: Neurobiology of zinc and zinc-containing neurons. Int Rev Neurobiol, 31, 145-238 (1989)

75. M. A. Greenough, J. Camakaris and A. I. Bush: Metal dyshomeostasis and oxidative stress in Alzheimer's disease. Neurochem Int, 62(5), 540-55 (2013) doi:10.1016/j.neuint.2012.08.014

76. X. Wang, B. Su, H. G. Lee, X. Li, G. Perry, M. A. Smith and X. Zhu: Impaired balance of mitochondrial fission and fusion in Alzheimer's disease. J Neurosci, 29(28), 9090-103 (2009) doi:10.1523/JNEUROSCI.1357-09.2009

77. X. C. Li, Y. Hu, Z. H. Wang, Y. Luo, Y. Zhang, X. P. Liu, Q. Feng, Q. Wang, K. Ye, G. P. Liu and J. Z. Wang: Human wild-type full-length tau accumulation disrupts mitochondrial dynamics and the functions via increasing mitofusins. Sci Rep, 6, 24756 (2016) doi:10.1038/srep24756 
78. C. P. Ramsey, C. A. Glass, M. B. Montgomery, K. A. Lindl, G. P. Ritson, L. A. Chia, R. L. Hamilton, C. T. Chu and K. L. Jordan-Sciutto: Expression of Nrf2 in neurodegenerative diseases. $J$ Neuropathol Exp Neurol, 66(1), 75-85 (2007) doi:10.1097/nen.0b013e31802d6da9

79. T. Ali, T. Kim, S. U. Rehman, M. S. Khan, F. U. Amin, M. Khan, M. Ikram and M. O. Kim: Natural Dietary Supplementation of Anthocyanins via PI3K/Akt/Nrf2/HO-1 Pathways Mitigate Oxidative Stress, Neurodegeneration, and Memory Impairment in a Mouse Model of Alzheimer's Disease. Mol Neurobiol, 55(7), 6076-6093 (2018) doi:10.1007/s12035-017-0798-6

80. X. Yu and Y. Li: Effect of Quercetin on PC12 Alzheimer's Disease Cell Model Induced by A $\beta$ (25-35) and Its Mechanism Based on Sirtuin1/Nrf2/HO-1 Pathway, 2020, 8210578 (2020) doi:10.1155/2020/8210578

81. R. Wang, Z. Yu, B. Sunchu, J. Shoaf, I. Dang, S. Zhao, K. Caples, L. Bradley, L. M. Beaver, E. Ho, C. V. Löhr and V. I. Perez: Rapamycin inhibits the secretory phenotype of senescent cells by a Nrf2-independent mechanism. Aging Cell, 16(3), 564-574 (2017) doi:10.1111/acel.12587

82. J. S. Talboom, R. Velazquez and S. Oddo: The mammalian target of rapamycin at the crossroad between cognitive aging and Alzheimer's disease. NPJ Aging Mech Dis, 1, 15008 (2015) doi:10.1038/npjamd.2015.8

83. A. Caccamo, C. Branca, J. S. Talboom, D. M. Shaw, D. Turner, L. Ma, A. Messina, Z. Huang, J. Wu and S. Oddo: Reducing Ribosomal Protein S6 Kinase 1 Expression Improves Spatial Memory and Synaptic Plasticity in a Mouse Model of Alzheimer's Disease. J Neurosci, 35(41), 14042-56 (2015) doi:10.1523/jneurosci.2781-15.2015

84. A. Caccamo, V. De Pinto, A. Messina, C. Branca and S. Oddo: Genetic reduction of mammalian target of rapamycin ameliorates Alzheimer's disease-like cognitive and pathological deficits by restoring hippocampal gene expression signature. J Neurosci, 34(23), 7988-98 (2014) doi:10.1523/jneurosci.0777-14.2014

85. A. Caccamo, A. Magri, D. X. Medina, E. V. Wisely, M. F. Lopez-Aranda, A. J. Silva and S. Oddo: mTOR regulates tau phosphorylation and degradation: implications for Alzheimer's disease and other tauopathies. Aging Cell, 12(3), 370-80 (2013) doi:10.1111/acel.12057

86. A. Caccamo, S. Majumder, A. Richardson, R. Strong and S. Oddo: Molecular interplay between mammalian target of rapamycin (mTOR), amyloid-beta, and Tau: effects on cognitive impairments. J Biol Chem, 285(17), 13107-20 (2010) doi:10.1074/jbc.M110.100420

87. J. Halloran, S. A. Hussong, R. Burbank, N. Podlutskaya, K. E. Fischer, L. B. Sloane, S. N. Austad, R. Strong, A. Richardson, M. J. Hart and V. Galvan: Chronic inhibition of mammalian target of rapamycin by rapamycin modulates cognitive and non-cognitive components of behavior throughout lifespan in mice. Neuroscience, 223, 102-13 (2012) doi:10.1016/j.neuroscience.2012.06.054

88. N. Duval, G. N. Vacano and D. Patterson: Rapamycin Treatment Ameliorates Age-Related Accumulation of Toxic Metabolic Intermediates in Brains of the Ts65Dn Mouse Model of Down Syndrome and Aging. Front Aging Neurosci, 10, 263 (2018) doi:10.3389/fnagi.2018.00263

89. R. Selvarani, S. Mohammed and A. Richardson: Effect of rapamycin on aging and age-related diseases_past and future. GeroScience, 43(3), 1135-1158 (2021) doi:10.1007/s11357-020-00274-1 90. P. Spilman, N. Podlutskaya, M. J. Hart, J. Debnath, O. Gorostiza, D. Bredesen, A. Richardson, R. Strong and V. Galvan: Inhibition of mTOR by rapamycin abolishes cognitive deficits and reduces amyloid-beta levels in a mouse model of Alzheimer's disease. PloS one, 5(4), e9979-e9979 (2010) doi:10.1371/journal.pone.0009979

91. D. L. Castillo-Carranza, A. N. Nilson, C. E. Van Skike, J. B. Jahrling, K. Patel, P. Garach, J. E. 
Gerson, U. Sengupta, J. Abisambra, P. Nelson, J. Troncoso, Z. Ungvari, V. Galvan and R. Kayed: Cerebral Microvascular Accumulation of Tau Oligomers in Alzheimer's Disease and Related Tauopathies. Aging and disease, 8(3), 257-266 (2017) doi:10.14336/AD.2017.0112

92. H. Wang, J. Fu, X. Xu, Z. Yang and T. Zhang: Rapamycin Activates Mitophagy and Alleviates Cognitive and Synaptic Plasticity Deficits in a Mouse Model of Alzheimer's Disease. J Gerontol A Biol Sci Med Sci, 76(10), 1707-1713 (2021) doi:10.1093/gerona/glab142

93. A.-L. Lin, W. Zheng, J. J. Halloran, R. R. Burbank, S. A. Hussong, M. J. Hart, M. Javors, Y.-Y. I. Shih, E. Muir, R. Solano Fonseca, R. Strong, A. G. Richardson, J. D. Lechleiter, P. T. Fox and V. Galvan: Chronic rapamycin restores brain vascular integrity and function through NO synthase activation and improves memory in symptomatic mice modeling Alzheimer's disease. Journal of cerebral blood flow and metabolism : official journal of the International Society of Cerebral Blood Flow and Metabolism, 33(9), 1412-1421 (2013) doi:10.1038/jcbfm.2013.82

94. S. Ozcelik, G. Fraser, P. Castets, V. Schaeffer, Z. Skachokova, K. Breu, F. Clavaguera, M. Sinnreich, L. Kappos, M. Goedert, M. Tolnay and D. T. Winkler: Rapamycin attenuates the progression of tau pathology in P301S tau transgenic mice. PLoS One, 8(5), e62459 (2013) doi:10.1371/journal.pone.0062459

95. R. Siman, R. Cocca and Y. Dong: The mTOR Inhibitor Rapamycin Mitigates Perforant Pathway Neurodegeneration and Synapse Loss in a Mouse Model of Early-Stage Alzheimer-Type Tauopathy. PLoS One, 10(11), e0142340 (2015) doi:10.1371/journal.pone.0142340

96. M. Kaeberlein and V. Galvan: Rapamycin and Alzheimer's disease: Time for a clinical trial? Sci Transl Med, 11(476) (2019) doi:10.1126/scitranslmed.aar4289

97. J. M. Carosi and T. J. Sargeant: Rapamycin and Alzheimer disease: a double-edged sword? Autophagy, 15(8), 1460-1462 (2019) doi:10.1080/15548627.2019.1615823

98. M. V. Clavijo Jordan, S.-T. Lo, S. Chen, C. Preihs, S. Chirayil, S. Zhang, P. Kapur, W.-H. Li, L. M. De Leon-Rodriguez, A. J. M. Lubag, N. M. Rofsky and A. D. Sherry: Zinc-sensitive MRI contrast agent detects differential release of $\mathrm{Zn}$ (II) ions from the healthy vs. malignant mouse prostate. Proceedings of the National Academy of Sciences, 113(37), E5464 (2016) doi:10.1073/pnas.1609450113

99. E. Rodriguez-Vieitez, R. Ni, B. Gulyás, M. Tóth, J. Häggkvist, C. Halldin, L. Voytenko, A. Marutle and A. Nordberg: Astrocytosis precedes amyloid plaque deposition in Alzheimer APPswe transgenic mouse brain: a correlative positron emission tomography and in vitro imaging study. Eur J Nucl Med Mol Imaging, 42(7), 1119-32 (2015) doi:10.1007/s00259-015-3047-0

100. R. Ni, D. R. Kindler, R. Waag, M. Rouault, P. Ravikumar, R. Nitsch, M. Rudin, G. G. Camici, L. Liberale, L. Kulic and J. Klohs: fMRI Reveals Mitigation of Cerebrovascular Dysfunction by Bradykinin Receptors 1 and 2 Inhibitor Noscapine in a Mouse Model of Cerebral Amyloidosis. Front Aging Neurosci, 11, 27 (2019) doi:10.3389/fnagi.2019.00027

101. R. Ni, B. Ji, M. Ono, N. Sahara, M. R. Zhang, I. Aoki, A. Nordberg, T. Suhara and M. Higuchi: Comparative In Vitro and In Vivo Quantifications of Pathologic Tau Deposits and Their Association with Neurodegeneration in Tauopathy Mouse Models. J Nucl Med, 59(6), 960-966 (2018) doi:10.2967/jnumed.117.201632

102. A. Ishikawa, M. Tokunaga, J. Maeda, T. Minamihisamatsu, M. Shimojo, H. Takuwa, M. Ono, R. Ni, S. Hirano, S. Kuwabara, B. Ji, M. R. Zhang, I. Aoki, T. Suhara, M. Higuchi and N. Sahara: In Vivo Visualization of Tau Accumulation, Microglial Activation, and Brain Atrophy in a Mouse Model of Tauopathy rTg4510. J Alzheimers Dis, 61(3), 1037-1052 (2018) doi:10.3233/jad170509 
103. M. Ono, N. Sahara, K. Kumata, B. Ji, R. Ni, S. Koga, D. W. Dickson, J. Q. Trojanowski, V. M. Lee, M. Yoshida, I. Hozumi, Y. Yoshiyama, J. C. van Swieten, A. Nordberg, T. Suhara, M. R. Zhang and M. Higuchi: Distinct binding of PET ligands PBB3 and AV-1451 to tau fibril strains in neurodegenerative tauopathies. Brain, 140(3), $764-780$ (2017) doi:10.1093/brain/aww339

104. R. Ni, Z. Chen, J. A. Gerez, G. Shi, Q. Zhou, R. Riek, K. P. R. Nilsson, D. Razansky and J. Klohs: Detection of cerebral tauopathy in P301L mice using high-resolution large-field multifocal illumination fluorescence microscopy. Biomedical Optics Express, 11(9), 4989-5002 (2020) doi:10.1364/BOE.395803 


\section{Figure Legends}

Figure 1. Effects of rapamycin on the expressions of mTOR/P70S6K and Nrf2/HO-1 signaling pathways in zinc treated SH-SY5Y cells and rat. (A, B) Representative blots and quantification of expression levels of p-mTOR S2448, T-mTOR, p-P70S6K T389, T-P70S6K in SH-SY5Y cells of control, zinc and zinc+rapamycin groups, $n=3$ cell experiment per group. (C, D) Representative blots and quantification of expression levels of HO-1 and Nrf2 are detected in cells of control, zinc and zinc+rapamycin groups. $\mathrm{n}=3$ cell experiment per group; (E, F) Representative blots and quantification of expression levels of p-mTOR S2448, T-mTOR, p-nP70S6K T389, TP70S6K in rats of control, zinc and zinc+rapamycin groups. $n=4$ rats per group in the same membrane. $(\mathrm{G}, \mathrm{H})$ Representative blots and quantification of expression levels of HO-1 and Nrf2 in rats of control, zinc and zinc+rapamycin groups. $\mathrm{n}=4$ rats per group in the same membrane. Quantifications of the blots were normalized to $\beta$-tubulin. *p $<0.05$ vs. control group; \#p $<0.05$ vs. zinc+rapamycin treatment.

Figure 2. Rapamycin decreases the expression of p-tau S356 in SH-SY5Y cells. (A, B) Representative blots and quantification of expression levels of p-Tau S356 and T-tau (tau5) proteins in SH-SY5Y cells of control, zinc and zinc+rapamycin groups. $\mathrm{n}=3$ cell experiment per group; (C, D) Representative blots and quantification of expression levels of p-Tau S356, T-tau (tau5) protein in rats of control, zinc and zinc+rapamycin groups. $\mathrm{n}=4$ rats per group in the same membrane. ${ }^{*} \mathrm{p}<0.05$ vs. control group; \#p $<0.05$ vs. rapamycin treatment. Quantifications of the blots were normalized to $\beta$-tubulin.

Figure 3. Rapamycin suppressed ROS generation caused by zinc in SH-SY5Y cells. (A, B) Representative fluorescent staining and quantification of the mean fluorescence intensity of ROS determined by DCFH-DA staining in SH-SY5Y cells of control, zinc and zinc+rapamycin groups. Scale bar $=250 \mu \mathrm{m} . ; \mathrm{n}=3$ cell experiment per group, ${ }^{*} \mathrm{p}<0.05 v s$. control group; $\# \mathrm{p}<0.05 v s$. zinc+rapamycin treatment.

Figure 4. Rapamycin attenuated the increase in the expressions of 4-HNE caused by zinc both in vitro and in vivo. (A, B) Representative confocal images and quantification of the mean fluorescence intensity for immunofluorescence staining using anti-4-HNE antibody (red) in SHSY5Y cells in control, zinc and zinc+rapamycin groups, the scale bar $=50 \mu \mathrm{m}$; Nuclei is counterstained with DAPI (blue); (C, D) Representative blots and quantification of expression levels of 4$\mathrm{HNE}$ in rats of control, zinc and zinc+rapamycin groups. $\mathrm{n}=4$ rats per group in the same membrane. *p $<0.05 v s$. control group; \#p $<0.05 v s$. rapamycin treatment. Quantifications of the blots were normalized to $\beta$-tubulin.

Figure 5. Rapamycin prevents the DNA oxidation caused by zinc in SH-SY5Y cells and rats. (A, B) Representative confocal images and quantification of the mean fluorescence intensity for immunofluorescence staining using anti-8-OHdG antibody (green) in SH-SY5Y cells in control, zinc and zinc+rapamycin groups. Scale bar $=50 \mu \mathrm{m}$; Nuclei is counter-stained with DAPI (blue); Quantification of the mean fluorescent intensity of 8-OHdG staining in the SH-SY5Y cells of control, zinc and zinc+rapamycin groups, $\mathrm{n}=3$ cell experiment per group; $(\mathrm{C}, \mathrm{D})$ Representative confocal images and quantification of the mean fluorescence intensity for immunofluorescence 
staining using anti-8-OHdG antibody (green) in the CA1 areas of the brain of the rats in control, zinc and zinc+rapamycin groups. Nuclei is counter-stained with DAPI (blue). Scale bar $=75 \mu \mathrm{m}$, and $25 \mu \mathrm{m}$ (zoomed images); $\mathrm{n}=6$ rats per group. *p $<0.05$ vs. control group; \#p < 0.05 vs. zinc+rapamycin treatment.

Figure 6. The effect of rapamycin on the performance of MWM in zinc-induced rats. (A) Escape latency of the rats in all three groups (control (red), zinc-injected (grey), zinc+rapamycin treatment (green)) in the MWM test of each training day. (B) Representative number of platform crossings on day 7. (C) Representative time spent in the target quadrant on day 7. (D) Swimming speed in MWM on day 7. $\mathrm{n}=6$ rats per group, $* \mathrm{p}<0.05$ vs. control group; $\# \mathrm{p}<0.05$ vs. rapamycin treatment.

Figure 7. Rapamycin improved synaptic impairment caused by zinc both in SH-SY5Y cells and in rats. (A, B) Representative blots and quantification of expression levels of SNAP25, synaptophysin and PSD95 protein expressions in SH-SY5Y cells of control, zinc and zinc+rapamycin groups. $\mathrm{n}=3$ cell experiment per group; (C, D) Representative blots and quantification of expression levels of SNAP25, synaptophysin and PSD95 protein expressions in rats of control, zinc and zinc+rapamycin groups. $n=4$ rats per group in the same membrane, $* \mathrm{p}<$ 0.05 vs. control group; \#p < 0.05 vs. zinc+rapamycin treatment. Quantifications of the blots were normalized to $\beta$-tubulin. 


\section{A}

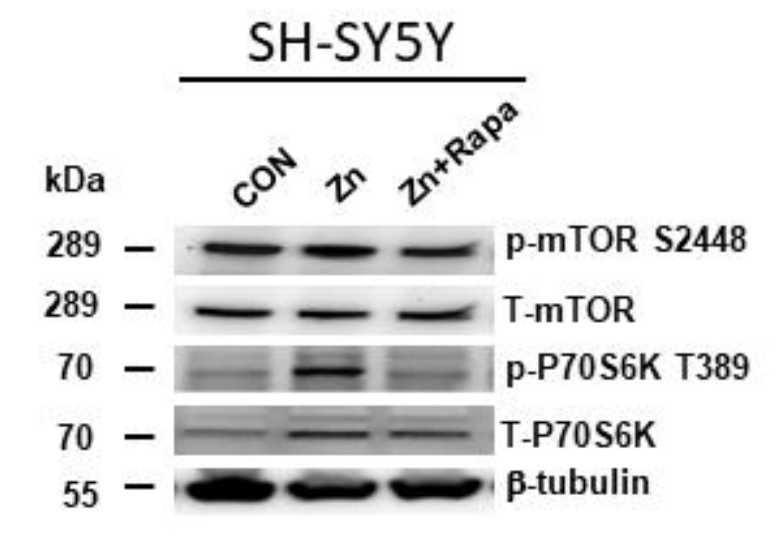

E

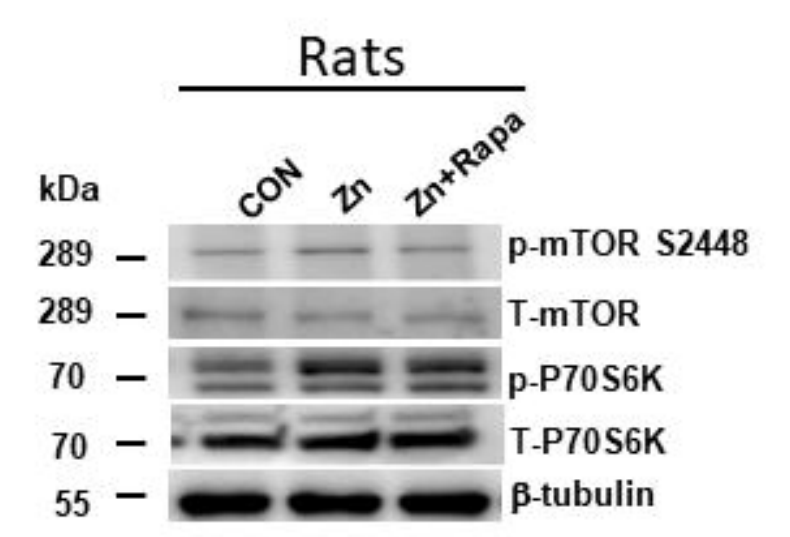

\section{B}

C

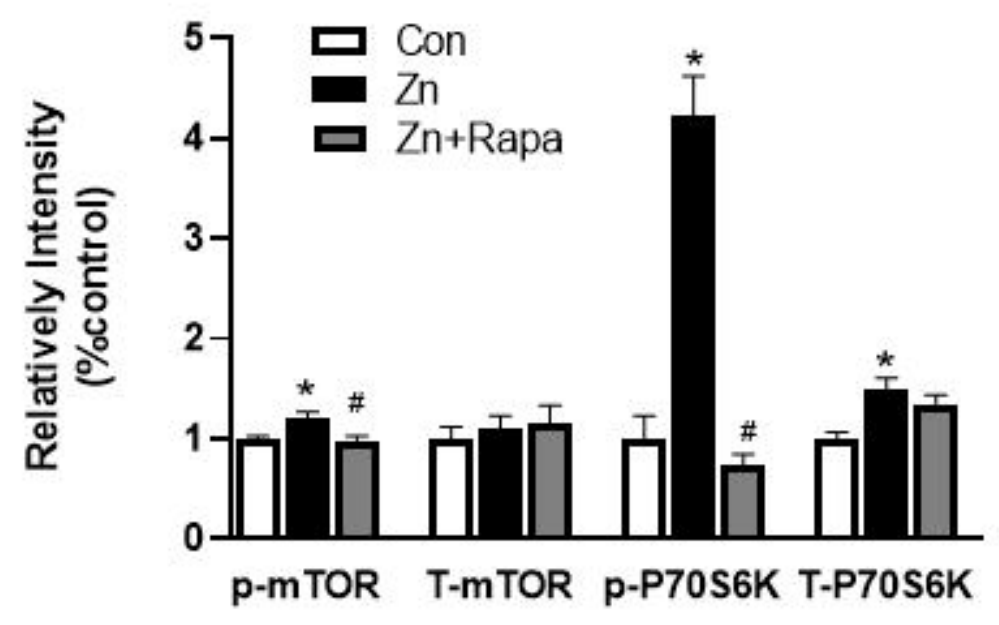

F

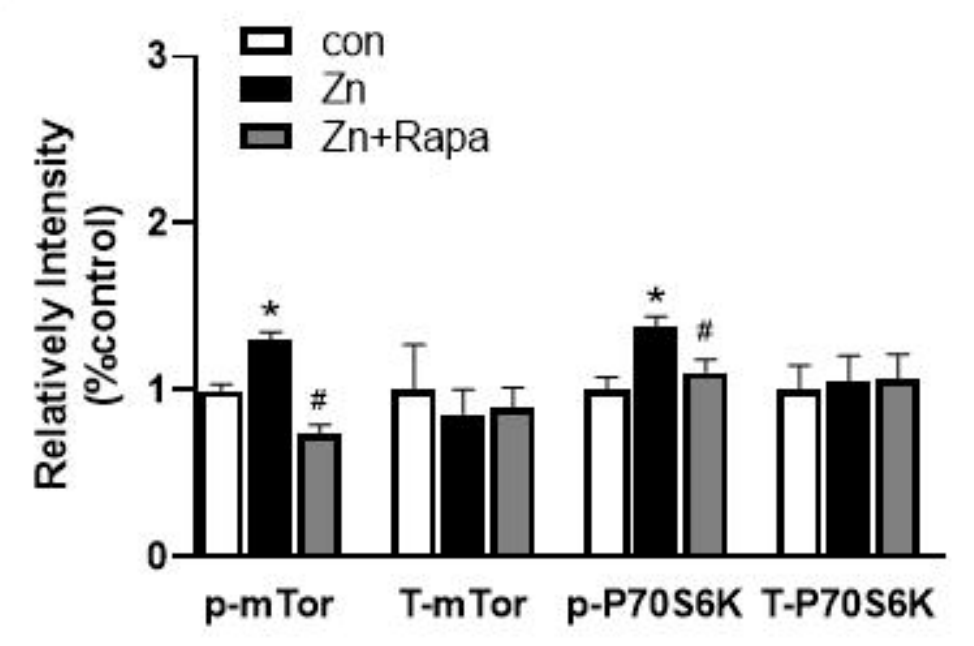

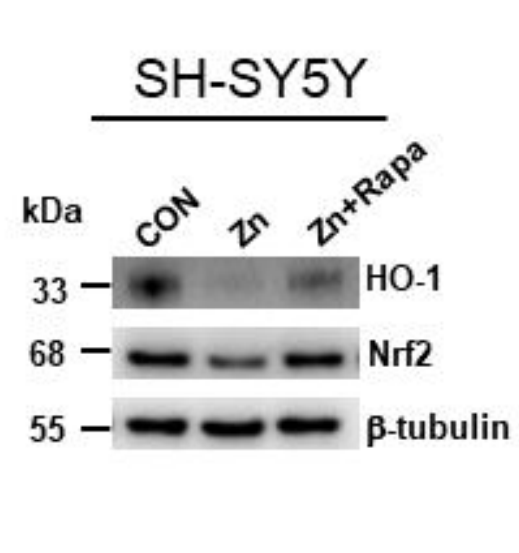

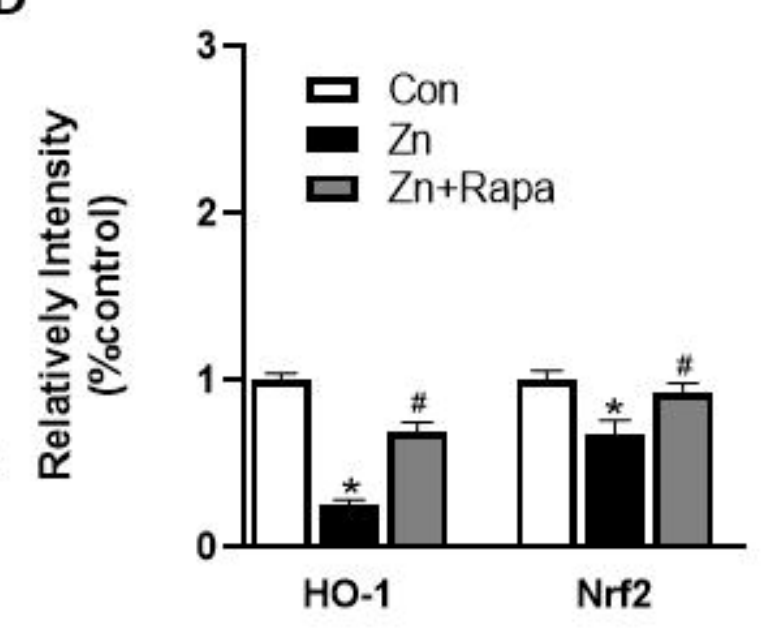

G

H

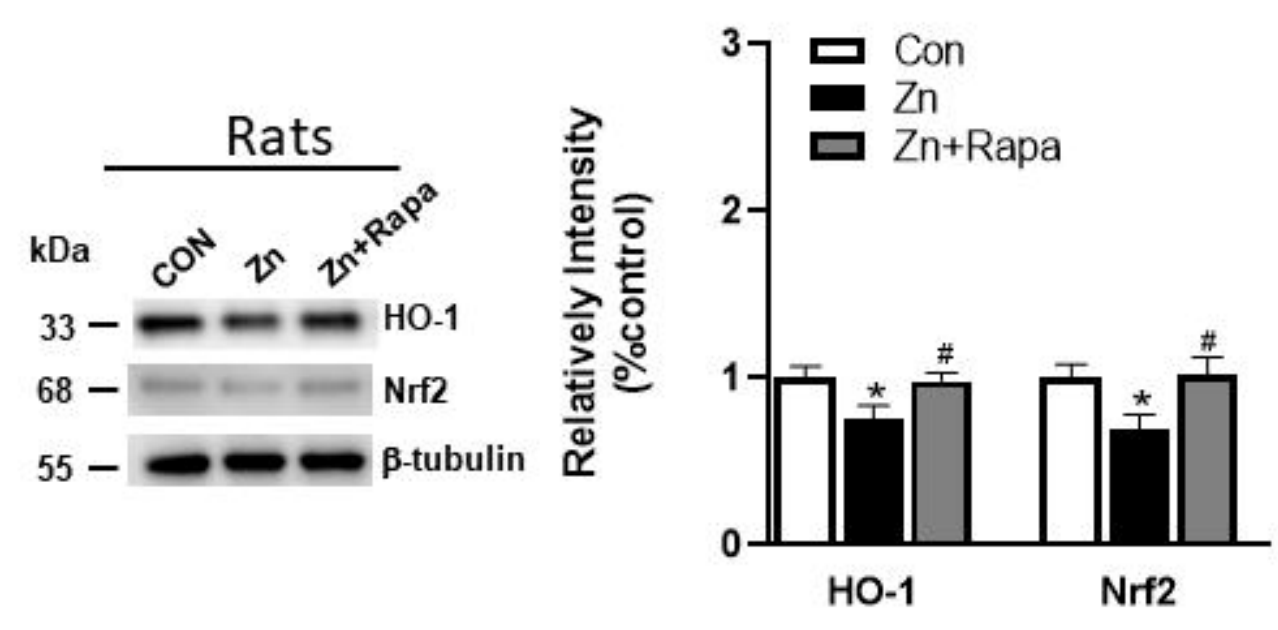


A

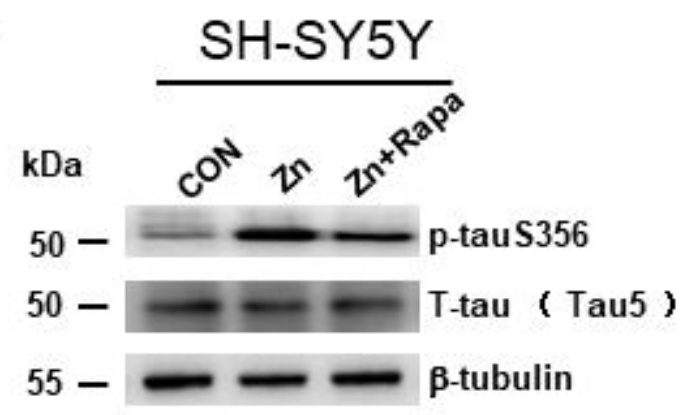

C

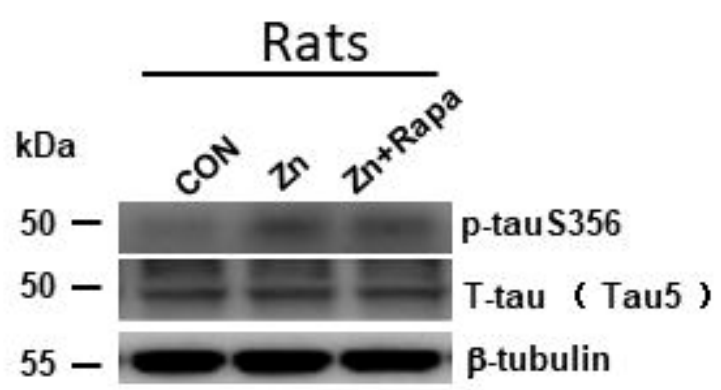

B

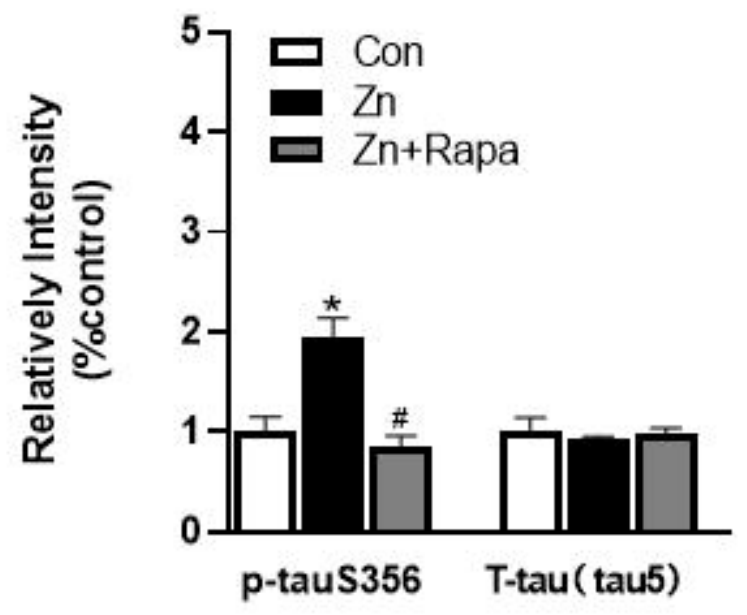

D

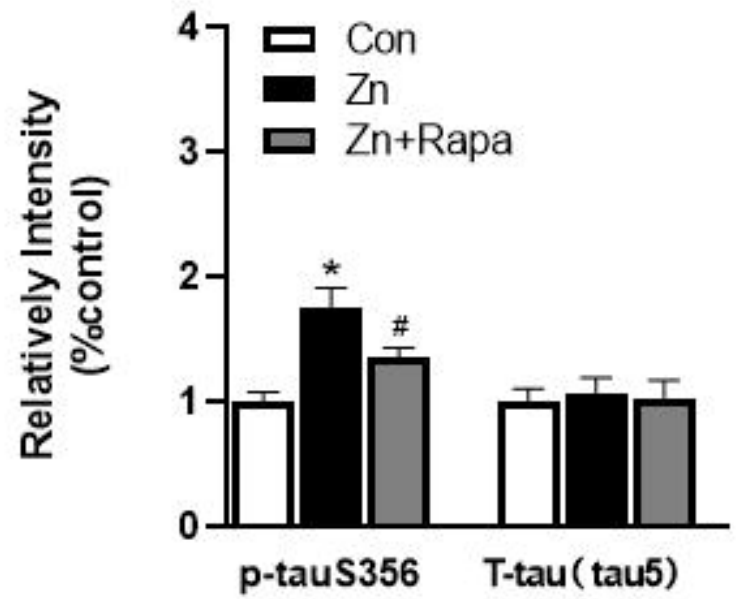


A

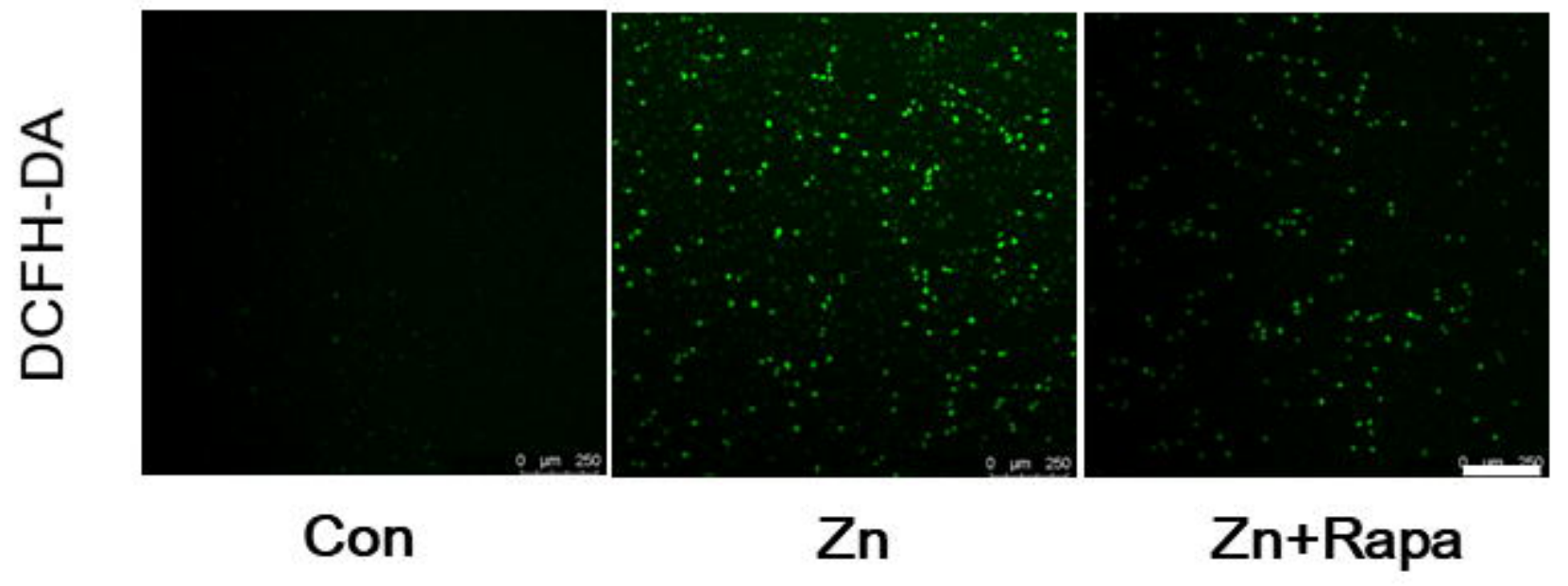

B

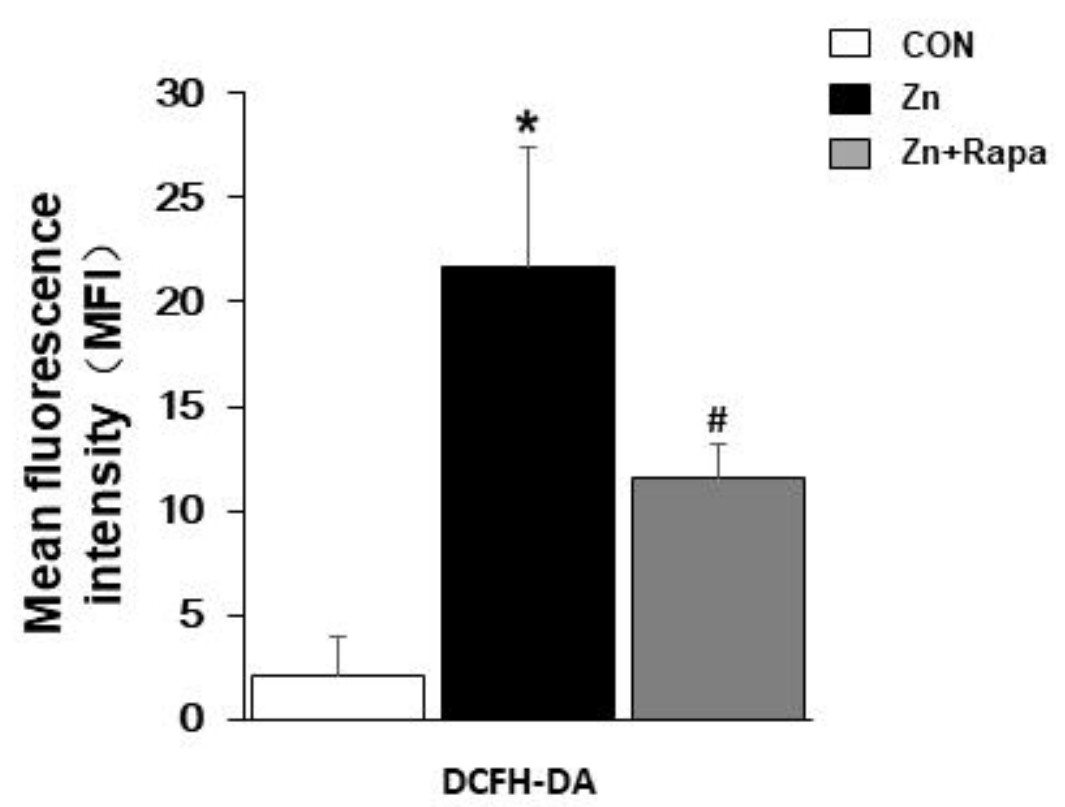




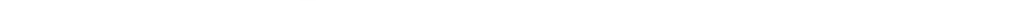


A

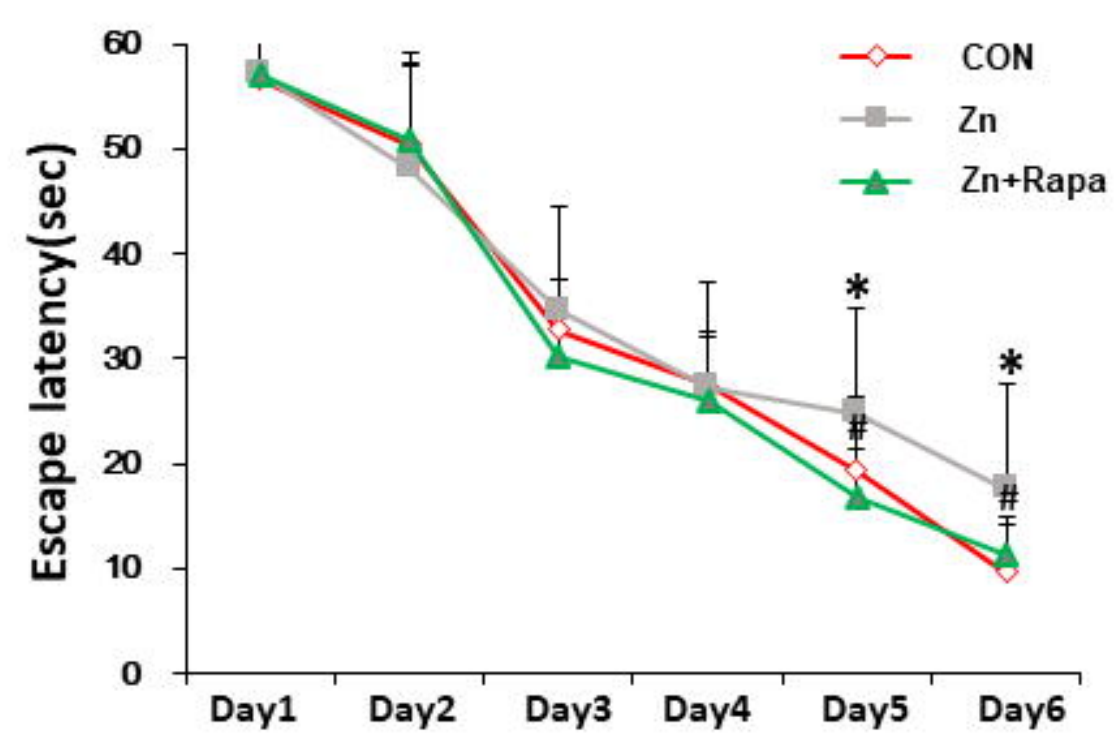

C

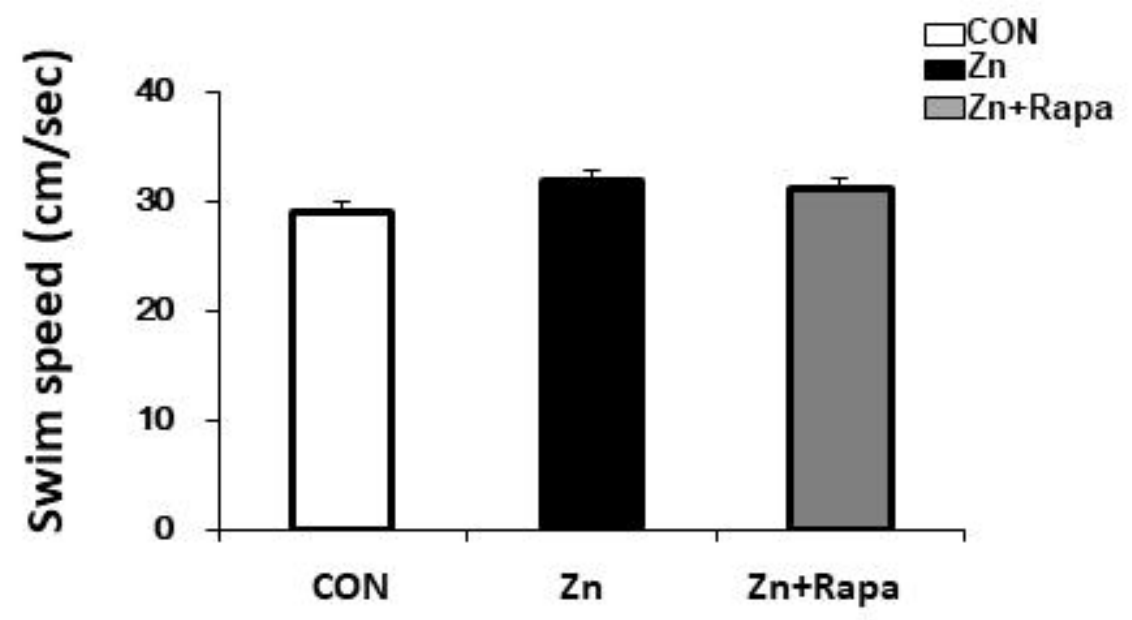

B

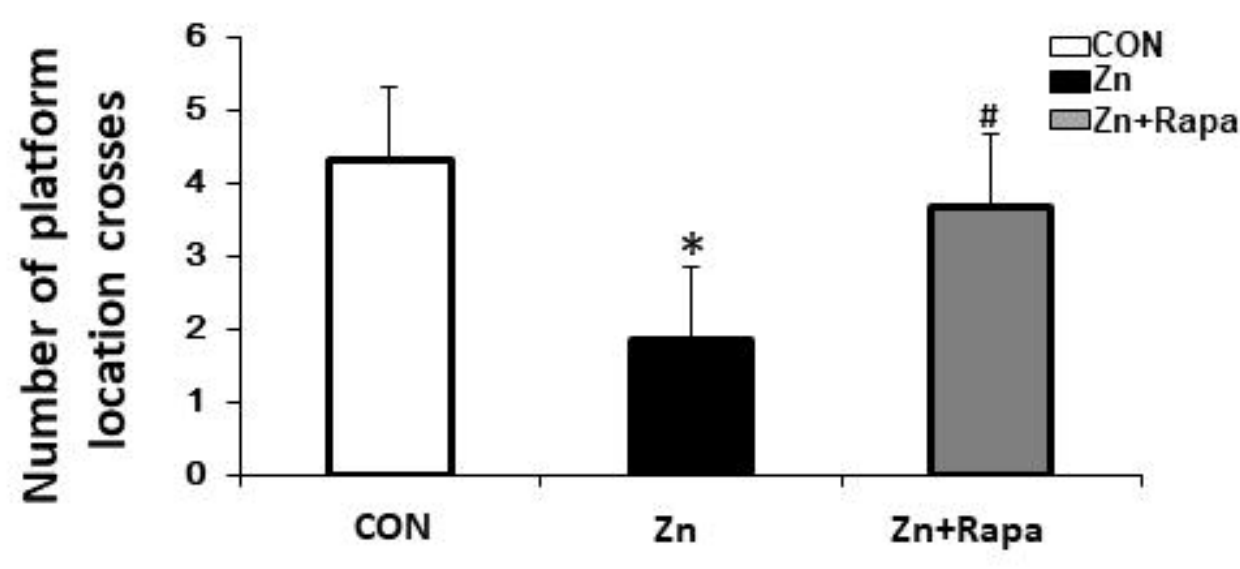

D

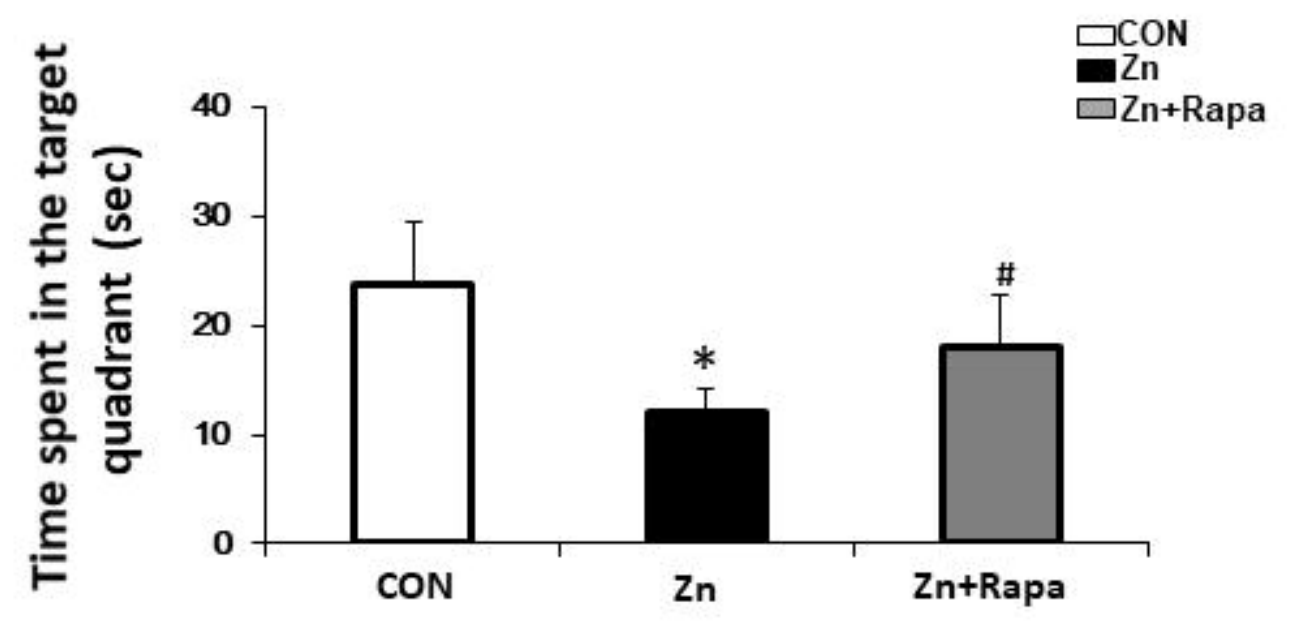



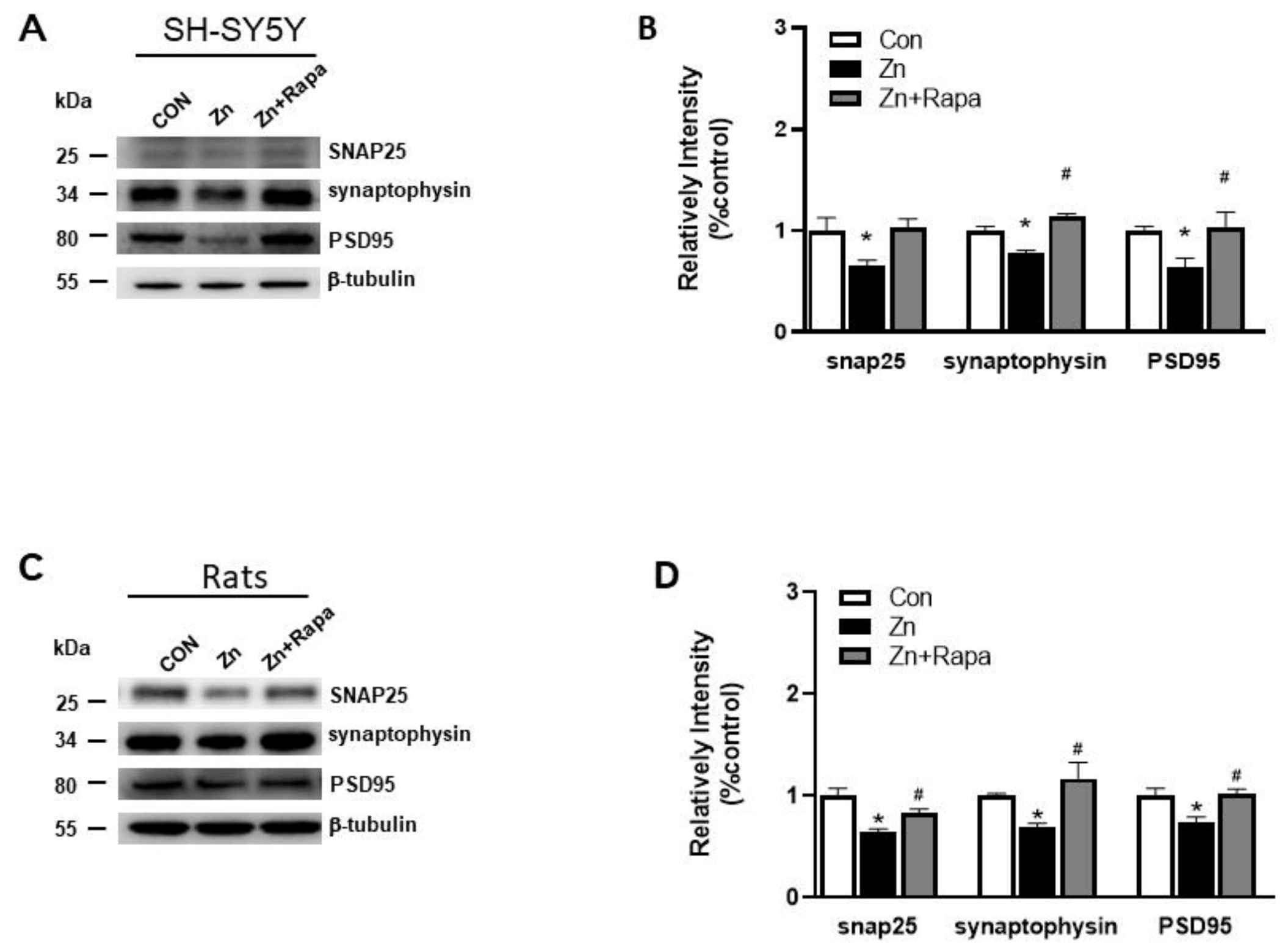